\title{
Influence of Cooling Rate on Microsegregation Behavior of Magnesium Alloys
}

\author{
Md. Imran Khan, ${ }^{1}$ Ahmad O. Mostafa, ${ }^{1}$ Mohammad Aljarrah, ${ }^{2}$ \\ Elhachmi Essadiqi, ${ }^{3}$ and Mamoun Medraj ${ }^{1}$ \\ ${ }^{1}$ Mechanical and Industrial Engineering Department, Concordia University, 1455 de Maisonneuve Boulevard West, \\ Montreal, QC, Canada H3G 1 M8 \\ ${ }^{2}$ Industrial Engineering Department, The Hashemite University, P.O. Box 330127, Zarqa 13115, Jordan \\ ${ }^{3}$ Renewable Energy \& Advanced Materials Research Lab, International University of Rabat, Technopolis, 11 100 Sala el Jadida, Morocco
}

Correspondence should be addressed to Mamoun Medraj; mmedraj@encs.concordia.ca

Received 28 November 2013; Revised 7 January 2014; Accepted 10 January 2014; Published 3 March 2014

Academic Editor: Necmettin Maraşlı

Copyright (C) $2014 \mathrm{Md}$. Imran Khan et al. This is an open access article distributed under the Creative Commons Attribution License, which permits unrestricted use, distribution, and reproduction in any medium, provided the original work is properly cited.

The effect of cooling rate on microstructure and microsegregation of three commercially important magnesium alloys was investigated using Wedge (V-shaped) castings of AZ91D, AM60B, and AE44 alloys. Thermocouples were distributed to measure the cooling rate at six different locations of the wedge casts. Solute redistribution profiles were drawn based on the chemical composition analysis obtained by EDS/WDS analysis. Microstructural and morphological features such as dendrite arm spacing and secondary phase particle size were analyzed using both optical and scanning electron microscopes. Dendritic arm spacing and secondary phase particle size showed an increasing trend with decreasing cooling rate for the three alloys. Area percentage of secondary phase particles decreased with decreasing cooling rate for AE44 alloy. The trend was different for AZ91D and AM60B alloys, for both alloys, area percentage of $\beta-\mathrm{Mg}_{17} \mathrm{Al}_{12}$ increased with decreasing cooling rate up to location 4 and then decreased slightly. The tendency for microsegregation was more severe at slower cooling rates, possibly due to prolonged back diffusion. At slower cooling rate, the minimum concentration of aluminum at the dendritic core was lower compared to faster cooled locations. The segregation deviation parameter and the partition coefficient were calculated from the experimentally obtained data.

\section{Introduction}

Environmental concern was the key motivating factor behind development of $\mathrm{Mg}$ alloys. Better aerodynamic design of vehicles or engines with improved combustion efficiency can lessen fuel consumption, but weight reduction seems to be the most effective way to achieve a substantial fuel saving $[1,2]$. Magnesium, with density of $1.74 \mathrm{~g} / \mathrm{cm}^{3}$, is the lightest of all the engineering structural metals [3]. Mg-based alloys have an excellent combination of properties which justifies their usage in transportation applications. These properties include excellent strength-to-weight ratio, good fatigue and impact strengths, and relatively large thermal and electrical conductivities [4].
All commercial magnesium alloys are multicomponent and form a variety of phases during solidification and subsequent processing stages. High-pressure die casting and gravity casting, particularly sand and permanent mold casting, are the common casting processes used to produce $\mathrm{Mg}$ alloy components. Other pertinent production technologies include squeeze casting, thixocasting, and thixomolding [5]. The wide range of operational conditions existing in foundry and casting processes generates, as a direct consequence, a diversity of solidification microstructures. Because microstructure determines the final properties of the material, proper understanding of the microstructure formation mechanisms is extremely important. Mechanical properties depend on the microstructural arrangement defined during 
solidification such as the amount and distribution of eutectic phases, grain size, dendrite spacing, and porosity [6]. Segregation or redistribution of solutes during solidification is closely linked to dendrite arm spacing, interdendritic porosity, and the amount and distribution of eutectic phases.

The mechanism of microsegregation during solidification of aluminum alloys has received considerable attention, but microsegregation during solidification of magnesium alloys has not been systematically studied. To understand the influence of cooling rate on microsegregation of magnesium alloys, this work aims to carry out an experimental investigation using wedge cast samples of AZ91D, AM60B, and AE44 alloys. By applying the wedge casting solidification technique, it is possible to produce a range of cooling rates in one casting.

\section{Literature Data}

Very few experimental works [7-10] regarding the microsegregation analysis of magnesium alloys were found in the literature. In contrary, several studies [11-20] were carried out to investigate the solidification behavior of magnesiumbased alloys. Although the prime focus of these studies was not on microsegregation analysis, valuable information regarding elemental composition at different cooling rates and conditions could be obtained from them. Mirković and Schmid-Fetzer $[8,9]$ studied the microsegregation of AZ31 and AM50 alloys, applying directional solidification technique. They reported that the segregation behavior of manganese is opposite compared to both aluminum and zinc. This can be explained by understanding the ternary Mg-Al-Mn system, where the Mn forms a peritectic system. Peritectic systems are known to show reversed segregation. Zhang et al. [10] studied the microsegregation in directionally solidified $\mathrm{Mg}-4 \mathrm{Al}$ binary alloy. They determined microsegregation in specimens directionally solidified with cooling rates ranging from 0.06 to $0.8 \mathrm{~K} / \mathrm{s}$. They reported that the concentration profile of $\mathrm{Al}$ at high growth rate or higher cooling rate is closer to the Scheil model. Zheng et al. [7] investigated the microsegregation pattern of $\mathrm{Mg}-4 \mathrm{Al}$ $4 \mathrm{Ca}$ alloy under different growth rates using the directional solidification technique. They suggested that the Scheil model can be used in microstructure simulation of this alloy as the microsegregation of the alloying elements ( $\mathrm{Al}$ and $\mathrm{Ca}$ ) predicted by this model agreed reasonably well with the EPMA measurements.

Wei and Warren [21] carried out microstructural characterization of several magnesium alloys in the AM series in as-cast condition. They performed quantitative analysis of the $\mathrm{Al}$ segregation in the die cast alloys by examining thin foil specimens in the TEM. Compositional measurements across an $\alpha$-Mg grain in AM50A at intervals of $180 \mathrm{~nm}$ were performed using X-ray energy dispersive spectrometry (EDS) in the TEM along a straight line. They found that the $\mathrm{Al}$ composition in the interior of $\mathrm{Mg}$ grain was approximately $1.5 \mathrm{wt} \%$ which increased to $3.0 \mathrm{wt}$. $\%$ in the area adjacent to the grain boundaries. They repeated the same procedure for a thin foil sample of die cast AM60A at intervals of $600 \mathrm{~nm}$. The $\mathrm{Al}$ content varied from $2 \mathrm{wt} . \%$ in the grain interior to approximately $4 \mathrm{wt} . \%$ in the Al-rich grain boundary region.
The width of the high $\mathrm{Al}$ region was about $2-3 \mathrm{~mm}$. They also reported that, owing to the low $\mathrm{Al}$ content, no $\beta-\mathrm{Al}_{12} \mathrm{Mg}_{17}$ formed in AM20, but there was intergranular Al segregation.

Barbagallo et al. [19] determined the variation of the alloying element contents through the grain boundaries of an HPDC AM60 alloy by means of EPMA line scanning and reported that the $\mathrm{Al}$ concentration varied from $2.5 \mathrm{wt} . \%$ in the bulk $\alpha-\mathrm{Mg}$ core to $10 \mathrm{wt} . \%$ in the boundary region. It is to be noted that for the same alloy AM60, Wei and Warren [21] and Barbagallo et al. [19] reported different amount of $\mathrm{Al}$ content in the grain boundary region, and this is due to the fact that the casting conditions of the samples were different. Han et al. [22] reported that for permanent mold casting of AZ91D alloy in the dendritic center the aluminum concentration is $2.6 \mathrm{wt} . \%$, but it is $11.7 \mathrm{wt} . \%$ at the dendrite edge, about 4.5 times higher than that in the dendrite center. Zhang et al. [23] conducted experiments to compare the amount of microsegregation in permanent mold cast and die-cast AZ91 alloys. They reported that the average concentration of $\mathrm{Al}$ and $\mathrm{Zn}$ is lower in the die casting matrix than in the permanent mold casting matrix. Average concentration of $\mathrm{Al}$ is $3.3 \mathrm{wt} \%$ and for $\mathrm{Zn}$ it is 0.33 wt. $\%$, in permanent mold casting and 3 wt. $\% \mathrm{Al}$ and 0.22 wt. $\% \mathrm{Zn}$ in die-cast matrix, which means the amount of segregation was higher for comparatively faster cooling. Ditze and Schwerdtfeger [24] reported on strip casting of AZ91 alloy that the aluminum content increased from $1 \mathrm{wt} . \%$ at the center of the dendrite arms where solidification had started to about $2.5 \mathrm{wt} . \%$ between the arms where solidification had ended. Guo et al. [25] reported that in AZ80 alloy the regions close to the $\beta-\mathrm{Mg}_{17} \mathrm{Al}_{12}$ eutectic phase have higher aluminum contents and that the maximum concentration in the dendritic interstice varied between $6.6 \mathrm{wt} . \%$ and $7.9 \mathrm{wt} . \%$. They also reported that applying electromagnetic vibration on the billet they could increase the value of minimum $\mathrm{Al}$ concentration up to $3.5 \mathrm{wt} . \%$ from $2.5 \mathrm{wt} . \%$, which is the minimum concentration of $\mathrm{Al}$ in the $\alpha-\mathrm{Mg}$ matrix in the center of a conventional die-cast billet. This means that they could reduce the amount of microsegregation by agitating the liquid. Table 1 summarizes the available data from the literature.

Segregation takes place due to unequal solute diffusion rates in the solid and the liquid phases of the solvent material. As a result, the phases that solidify in the later stages of the solidification process, such as $\beta-\mathrm{Mg}_{17} \mathrm{Al}_{12}$, are placed between dendrite arms. Gungor [26] reported that the extent of microsegregation in an alloy could be determined experimentally by measuring one of the following: amount of nonequilibrium eutectic, amount of nonequilibrium second phase, minimum solid composition, ratio of minimum and maximum composition of the primary phase, and composition versus fraction solid profile. Experimental techniques to investigate the extent of microsegregation include quantitative metallography (point count, areal, and lineal measurements), X-ray diffraction analysis [27], and electron microprobe measurements.

Of the techniques available, the most widely used one for characterizing microsegregation is the random sampling approach developed by Flemings et al. [28], commonly 
known as the point matrix or area scan approach. There is no hard and fast rule about the total number of points to be taken to represent the compositional variability. Gungor [26] reported that at least 100 points are necessary to obtain a reasonably accurate result. He showed that the result did not vary significantly if 300 points are taken instead of 100 points. These points are acquired by means of scanning electron microscope-energy dispersive spectroscopy (SEMEDS) or electron microprobe analysis using wavelength dispersive spectrometry (EPMA-WDS). Two comparatively less applied methods are compositional maps and segregation ratio. With compositional maps it is possible to present the nature and variability of the dendritic structure and associated microsegregation, but it is not a suitable method for comparing different samples. The segregation ratio usually refers to the maximum over minimum or the maximum over bulk composition. These are the simplest parameters for comparing different samples, but much information is lost. Martorano and Capocchi [29] used a refined segregation ratio, and the average deviation between the measurements and nominal composition were reported.

Two approaches were suggested to sort the EPMA data points into increasing or decreasing order depending on their segregation behavior to produce composition versus solid fraction profiles for each element. These approaches are sorting all the measurements based on composition of a single component (single-element sorts) or sorting based on the compositional difference between two solutes (difference sorts). Yang et al. [30] reported that sorting based on primary alloying elements can produce more accurate elemental partition coefficients. However, the main weakness of both techniques lies in the appropriateness of the choice of the elements upon which to base the sort; for a 10-component alloy, there are 90 different permutations of the difference sorts to consider [31].

Ganesan et al. [31] proposed an alloy-independent sorting algorithm. They termed it weighted interval ranking sort (WIRS). In this approach, all elements present at each data point are considered along with the measurement errors accrued during data treatment. By applying this approach for segregation profiling of Ni-based alloys, they demonstrated that this sorting method treats eutectic constituents appropriately and the errors in the segregation profile are also more accurately determined. The WIRS method was applied in this work as this alloy independent sorting method could accurately treat the eutectic constituents of the three investigated multicomponent alloys.

Segregation ratio and segregation index: these two methods rely on the minima or maxima of an alloying element at a particular location to calculate segregation severity. These calculations might be sometimes misleading as only the terminal points of solute profiles are being considered instead of the entire variation. Poirier [32] proposed the segregation deviation parameter method for measuring the severity of microsegregation. This method is better in the sense that the deviation is calculated over the entire range of data

$$
\sigma_{m}=\frac{1}{n C_{0}} \sum_{i=1}^{n}\left|C_{i}-C_{0}\right| \text {. }
$$

In this method, the segregation deviation parameter $\sigma_{m}$ is calculated using (1). The absolute difference between the composition at any point $C_{i}$ and the bulk composition $C_{0}$ is measured and the sum is taken for all the readings. Then, this summation is divided by the total number of points analyzed and the bulk composition.

Both the segregation deviation parameter and the segregation index were employed in this work to compare the severity of microsegregation at different locations of the wedge cast samples.

\section{Analytical Microsegregation Modeling}

Several analytical microsegregation models [27, 33-38] have been found in the literature to model the solute redistribution of alloying elements during dendritic solidification of alloys. In most of the models, mass balance for the solute elements is considered within a simplified geometry such as a plane, cylinder, or sphere to describe the growth of dendrite arms. It is obvious from theoretical and experimental evidence that the simplified geometry gives reasonably accurate results for the majority of alloy systems and solidification processes [39-41]. The simplest formulations are the equilibrium solidification model (lever rule) and Scheil-Gulliver model, which describe the two extreme cases of ideal equilibrium and nonequilibrium, respectively. With the advent of more sophisticated computing technology and improvement of material databases, the more advanced models (Kraft et al. [40], Du and Jacot [42], Boettinger et al. [43]) incorporate more realistic variable diffusion properties across the solid-liquid interface. Three models will be described in the following section: equilibrium solidification model, the Scheil-Gulliver solidification model, and the Brody-Flemings dendritic solidification model.

3.1. Equilibrium Solidification Model. This model assumes that a state of equilibrium exists at the solid-liquid interface during growth. That means there would be negligible resistance for transportation of atoms between the solid and liquid phases [44]. For instance, if a single crystal of alloy composition $C_{0}$ is cooled to temperature $\left(T^{*}\right)$, which is below the liquidus temperature $\left(T_{L}\right)$, then according to the equilibrium solidification theory, $C_{L}^{*}$ and $C_{S}^{*}$ would be the respective compositions of liquid and solid at the interface. The partition coefficient $K$ is the ratio of the composition of the solid to that of the liquid. It indicates the degree of segregation of solute. The equilibrium partition ratio may be defined as follows:

$$
K=\frac{C_{S}^{*}}{C_{L}^{*}}
$$

A value less than unity indicates that the element is partitioning preferentially to the eutectic region, whereas a value greater than unity indicates that the element is partitioning to the dendrite core as peritectic solidification. The farther from unity the partition coefficient, the more strongly the element partitions to either the dendrite core or eutectic region. Physical parameters that contribute to 
the partition coefficient are differences in atomic radii (the tendency for an element to be in solution) and the chemical potential of the elements in the liquid.

Applying the equilibrium lever rule the amount of solute redistribution during equilibrium solidification can be determined by

$$
C_{S} f_{S}+C_{L} f_{L}=C_{0}
$$

Here $f_{S}$ and $f_{L}$ are weight fractions of solid and liquid, respectively. The above equation can be written in the following form:

$$
C_{S}=\frac{K \cdot C_{0}}{\left(1-f_{S}\right)+K \cdot f_{S}} .
$$

This equation describes the composition of the solid phase with respect to the fraction of solid where $C_{S}$ is solute concentration in the solid (wt.\%), $C_{0}$ is the initial solute concentration (wt.\%), $K$ is the partition coefficient, and $f_{S}$ is the fraction solid.

According to the assumption of the equilibrium model, there would be complete diffusion in the liquid and solid phases that means the final product would have a homogeneous composition $C_{S}=C_{0}$ [44].

The dependency of liquidus temperature on the changing liquid composition would result in solidification of the alloys over a range of temperatures. The first solid would start forming and the composition would be lower in solute, for eutectic alloys, compared to initial liquid composition. As the solidification progresses, the balance of the solute would be rejected enriching the liquid through diffusion. This would eventually result in lower liquidus temperature than that of the initial composition. This solute rejection process is responsible for the development of segregation or coring. As a general rule, it can be stated that if the freezing range is larger for an alloy and it gets sufficient time for solute rejection, the segregation severity would be more [45].

3.2. Scheil-Gulliver Solidification Model. This model is different from the equilibrium model in the sense that it does not allow any elemental diffusion in the solid. This means that once a solid is formed nothing comes out of it or gets in. This would result in a steady rise in rejected solute level in the liquid phase until the final liquid region has reached the eutectic composition. The famous "nonequilibrium lever rule" or more popularly known as the Scheil equation is as follows:

$$
C_{S}=K \cdot C_{0}\left(1-f_{S}\right)^{K-1}
$$

3.3. Brody-Fleming Dendritic Solidification Model. The work of Bower et al. [35] pinpointed the reason for the discrepancy between experimental microsegregation measurements and the values predicted by the Scheil model. This mismatch is due to the presence of finite solid-state diffusion in actual castings, whereas the Scheil model assumes no diffusion in the solid state. Therefore, the amount of back diffusion that takes place, both during and after solidification, has to be taken into consideration. This back diffusion is responsible for lower solute levels than the prediction of the Scheil model. The extent of back diffusion is determined by the dimensionless parameter, $\alpha$, as shown in the integration of the differential solute balance equation for a parabolic growth rate as follows:

$$
C_{S}=K C_{0}\left[1-(1-2 \alpha K) f_{S}\right]^{(K-1) /(1-2 \alpha K)},
$$

where

$$
\alpha=\frac{4 D_{S} t_{f}}{\lambda^{2}} .
$$

Here, $D_{S}$ is the diffusivity in solid $\left(\mathrm{m}^{2} \cdot \mathrm{s}^{-1}\right), t_{f}$ is the local solidification time (s), and $\lambda$ represents the secondary dendrite arm spacing (m). Equation (6) contains two limiting cases that were described earlier for plane front solidification; when $\alpha$ is set to 0.5 , then the equation represents the equilibrium lever rule and when $D_{S}$ is set to zero (i.e., no solid state diffusion), $\alpha$ becomes zero, and that results in the Scheil equation.

There are many other models available in the literature, and the quest for achieving a perfect model is still going on. But most of these models are modifications of the BrodyFlemings model. Kearsey [46] in his thesis came to the conclusion that it is really difficult to make accurate microsegregation prediction using these simplified models, as these models do not take into account the complexity regarding the number of diffusing solute species and their relative interactive effects that takes place during the solidification of multicomponent alloys.

\section{Methodology}

The ingots of the three alloys were melted and degased using hexachloroethane $\left(\mathrm{C}_{2} \mathrm{Cl}_{6}\right)$. The pouring temperature of the molten metal in the mold was $1000 \mathrm{~K}$ or $723^{\circ} \mathrm{C}$. Six K-type thermocouples at different locations along the wedge casting were placed as illustrated in Figure 1(a). Time-temperature curves were obtained at each location using the thermocouple reading. The thickness increases gradually from $6 \mathrm{~mm}$ at location 1 to $34 \mathrm{~mm}$ at location 6 as shown in Figure 1(b). It is expected that location 1 has the fastest cooling rate, while location 6 has the slowest cooling rate of the six locations.

The bulk compositions of the investigated alloys are presented in Table 2. In AE44 alloy, rare earth elements were added as mischmetal. The percentage of the rare earth elements in the mischmetal is as follows: $\% \mathrm{Ce}=55.90, \% \mathrm{La}=$ $30.50, \% \mathrm{Pd}=6.80, \% \mathrm{Nd}=5.20$, and \%others $=1.60$.

Solidified samples were sectioned longitudinally at the position of the thermocouples. Samples were ground using $120,240,320,400,600,800$, and 1200 grit $\mathrm{SiC}$ emery paper, while ethanol was used as lubricant and the samples were ultrasonically cleaned in ethanol between steps to remove any residue. Samples were etched with nitric acid reagent (20 $\mathrm{mL}$ acetic acid, $1 \mathrm{~mL} \mathrm{HNO}_{3}$ (concentrated), $60 \mathrm{~mL}$ ethylene glycol, $20 \mathrm{~mL}$ water) after being manually polished. The solidification microstructures were analyzed by optical microscopy (OM). The phase analyses were investigated 


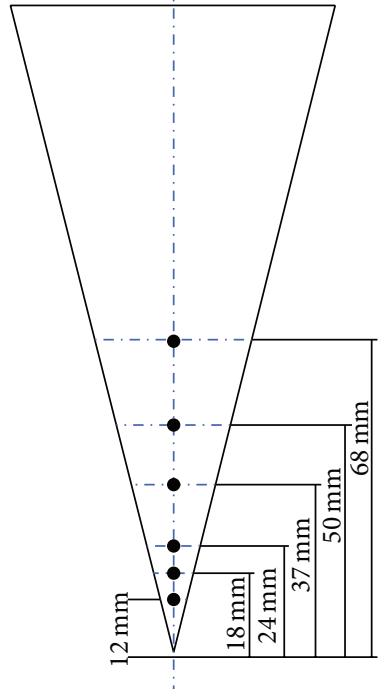

(a)

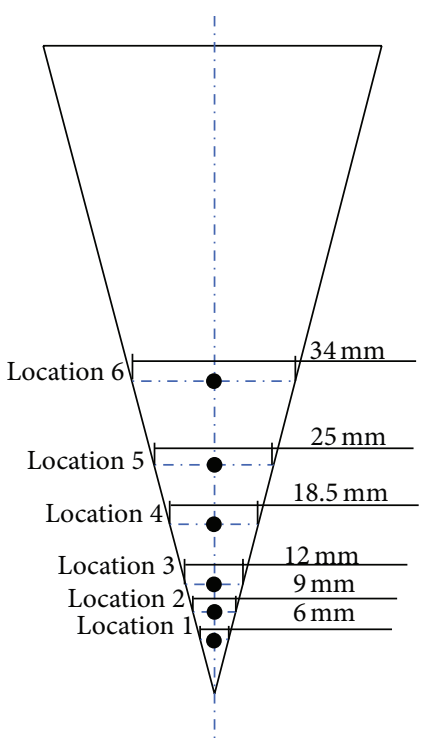

(b)
FIGURE 1: Schematic of thermocouple positions in the wedge cast sample.

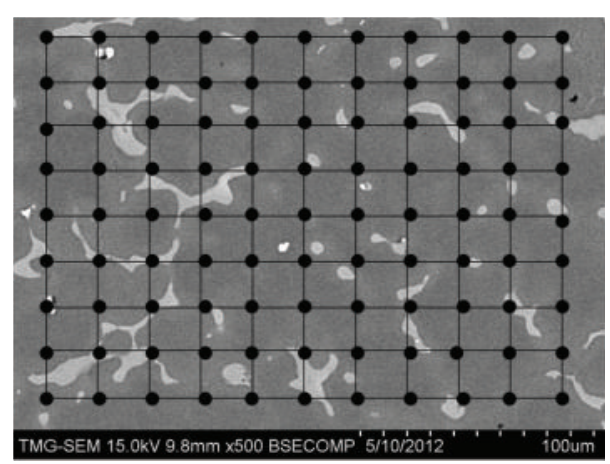

FIGURE 2: Schematic of area scan method using EDS. Each black dot corresponds to a composition measurement.

using scanning electron microscopy (SEM) (Model, Hitachi S-3400N SEM) equipped with wavelength dispersive spectrometry (WDS) and energy dispersive spectrometry (EDS) systems for elemental analysis. For the SEM, the samples were not etched.

The SEM was used mainly in the backscatter electron (BSE) mode at $15 \mathrm{keV}$. BSE images were treated by image analysis software in order to enhance the color contrast. The composition measurements for elemental analysis were carried out using EDS. At each sample location a minimum of 150 readings were taken in a matrix using EDS spot analysis as shown in Figure 2.

X-ray diffraction (XRD) using X'Pert PRO, manufactured by PANalytical Inc., was performed to detect the phases present in these alloys and measure the volume fraction of the dominant secondary phases. The samples' powders were prepared in a mortar to a uniform particle size distribution. Silicon powder ( -325 mesh) was added to all powder samples as an internal standard to correct for any systematic error. $\mathrm{X}$-ray diffraction analysis of the samples was carried out using
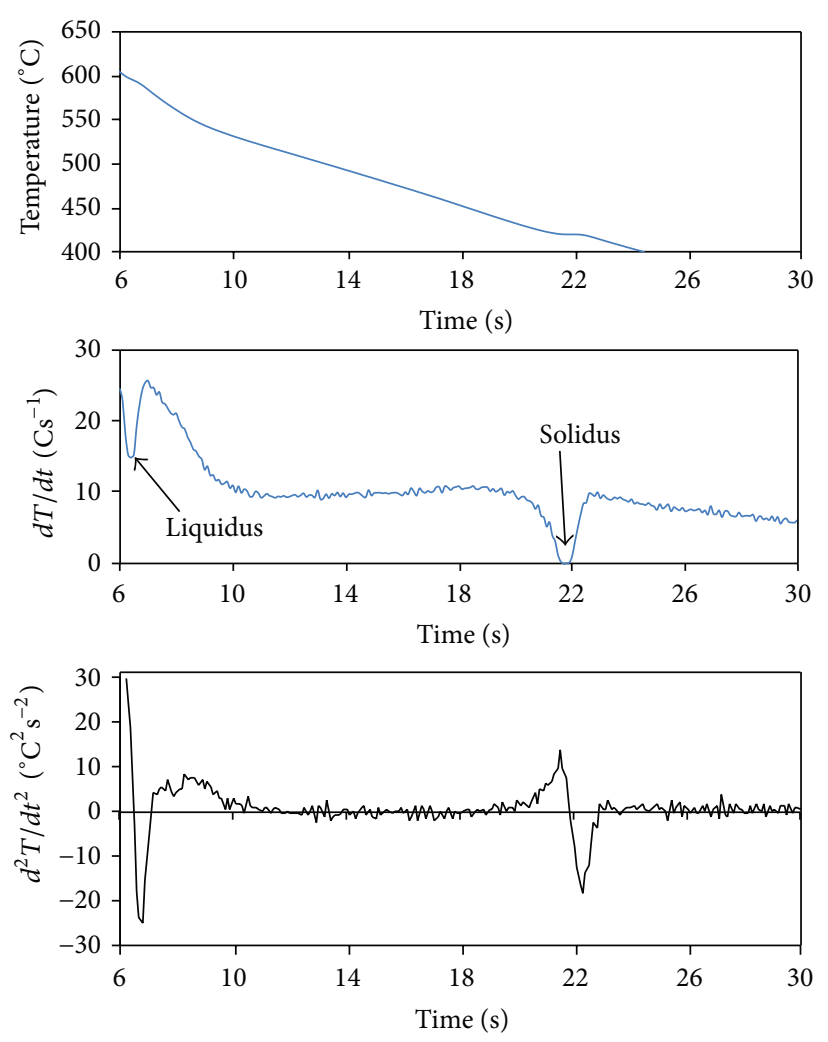

FIGURE 3: The cooling, first, and second derivative curves of the AZ91D alloy showing the solidus and liquidus.

X'Pert High Score Plus software in combination with the Rietveld analysis and Pearson's crystal database [47].

Secondary dendrite arm spacing was measured using the linear intercept method from optical micrographs. Suitable locations were selected where secondary dendrite arms are clearly distinguishable. Then the average secondary dendrite arm spacing was measured by counting the number of arms intercepting a straight line of a known length. Readings were taken at 10 different locations close to the thermocouple position in the wedge and then averaged.

\section{Results and Discussion}

5.1. Thermal Analysis. The cooling curves obtained at different locations of the wedge cast samples were analyzed to obtain important thermal parameters. A cooling curve contains information regarding the release of heat during solidification. This release of heat eventually changes the slope of the cooling curve which indicates the characteristics of transformation and phase reactions during solidification. However, the amount of the heat that evolved during some phase transformations is very small that it is difficult to detect these changes from the cooling curve alone. Hence, the first and second derivatives of the cooling curve were employed to determine these thermal parameters accurately. This procedure is presented in Figure 3 for location 1 of AZ91D alloy. The block arrows denote the approximate start and end of solidification as determined from temperatures at deviations from 
TABLE 1: Summary of the literature data.

\begin{tabular}{|c|c|c|c|c|c|c|}
\hline \multirow{2}{*}{ Alloy } & \multirow{2}{*}{ Casting condition } & \multirow{2}{*}{ Min. Al wt.\% } & \multirow{2}{*}{ Max. Al wt.\% } & \multicolumn{2}{|c|}{ Scheil model } & \multirow{2}{*}{ Reference } \\
\hline & & & & Min. Al wt.\% & Max. Al wt.\% & \\
\hline $\mathrm{Mg}-4 \mathrm{Al}-4 \mathrm{Ca}$ & DS* & 1 & $>3$ & 1 & 3 & \\
\hline AZ31 & DS & 1 & $4-5$ & 1 & $>6$ & [7] \\
\hline AM50 & DS & $<2$ & $8-9$ & $<2$ & $>10$ & {$[8,9]$} \\
\hline $\mathrm{Mg}-4 \mathrm{Al}$ & DS & $<2$ & $8-9$ & $<2$ & $>10$ & \\
\hline AM60 & HPDC $^{* *}$ & 2.5 & 10 & - & - & {$[10]$} \\
\hline AM50A & Die casting & 1.5 & 3.0 & - & - & [19] \\
\hline AM60A & Die casting & 2 & 4.0 & - & - & {$[21]$} \\
\hline AZ91D & $\mathrm{PMC}^{* * *}$ & 2.6 & 11.7 & - & - & \\
\hline AZ91D & PMC & 3.3 & - & - & - & {$[22]$} \\
\hline AZ91D & Die casting & 3 & - & - & - & {$[23]$} \\
\hline AZ91D & Strip casting & 1 & 2.5 & - & - & \\
\hline AZ80 & Die-cast billet & $2.5-3.5$ & $6.6-7.9$ & - & - & {$[24]$} \\
\hline
\end{tabular}

${ }^{*}$ DS: directional solidification; ${ }^{* *}$ HPCD: high-pressure die casting; ${ }^{* *}$ PMC: permanent mold casting.

TABLE 2: Bulk composition of the investigated alloys (wt.\%).

\begin{tabular}{lccccccc}
\hline Alloy & $\% \mathrm{Al}$ & $\% \mathrm{Zn}$ & $\% \mathrm{Mn}$ & $\% \mathrm{Si}$ & $\% \mathrm{Cu}$ & $\% \mathrm{Fe}$ & $\left.<\mathrm{Ce}^{(\% \mathrm{RE}}{ }^{*}\right)$ \\
\hline AE44 & 3.95 & 0.19 & 0.3 & 0.007 & $<0.005$ & $<0.005$ & $2.20\left(3.94^{*}\right)$ \\
AM60B & 5.7 & 0.023 & 0.31 & 0.013 & $<0.005$ & $<0.005$ & $<0.005$ \\
AZ91D & 8.8 & 0.75 & 0.34 & 0.015 & $<0.005$ & \\
\hline
\end{tabular}

* Percentage of the other rare earth elements in the mischmetal.

TABLE 3: Liquidus, solidus, and freezing range calculation of the three alloys.

\begin{tabular}{lccc}
\hline Alloy & Liquidus $\left({ }^{\circ} \mathrm{C}\right)$ & Solidus $\left({ }^{\circ} \mathrm{C}\right)$ & Freezing range $\left({ }^{\circ} \mathrm{C}\right)$ \\
\hline AZ91D & 600 & 410 & 190 \\
AM60B & 620 & 415 & 205 \\
AE44 & 630 & 575 & 55 \\
\hline
\end{tabular}

TABLE 4: Cooling rate of investigated alloys within the solidification range.

\begin{tabular}{lccc}
\hline Location & $\begin{array}{c}\text { Cooling rate }{ }^{\circ} \mathrm{C} / \mathrm{s} \\
\mathrm{AZ91D}\end{array}$ & $\begin{array}{c}\mathrm{AM} 60 \mathrm{~B} \\
\left(600^{\circ} \mathrm{C}-410^{\circ} \mathrm{C}\right)\end{array}$ & $\begin{array}{c}\mathrm{AE} 44 \\
\left(625^{\circ} \mathrm{C}\right)\end{array}$ \\
\hline 1 & 10.11 & 16.13 & 6.05 \\
2 & 11.32 & 16.55 & 7.79 \\
3 & 11.41 & 16 & 7.26 \\
4 & 10.15 & 11.87 & 5.84 \\
5 & 8.08 & 8.17 & 3.01 \\
6 & 5.18 & 5.02 & 1.49 \\
\hline
\end{tabular}

linearity in the first and second derivative curves. The results are summarized in Table 3 . The liquidus and solidus temperatures recorded at different wedge locations remain constant regardless of the change of cooling rate. From Table 3, it can be seen that the rare earth containing alloys have the smallest solidification range.

The cooling rates of the three investigated alloys at different thermocouple locations are presented in Table 4. For ease of calculation and representation, cooling rates were considered to be changing linearly within the approximate solidification range of the alloys. A little difference in cooling rate among the first three locations was noticed. Although it is considered that cooling rate decreases gradually from location 1 to location 6 , it is evident from the table that, for all three alloys, the cooling rate at location 2 is slightly higher than that at location 1 . The deviation observed at these thermocouple locations can possibly be explained by some phenomenological factors. Firstly, this could be due to the delay in thermocouple response to correctly record the temperature change in rapidly cooled locations. Secondly, the pattern of mold filling might also be responsible. The wedge cast sample is very narrow at the bottom and hence this narrow end could solidify much earlier, before the rest of the locations. But the molten metal on top of this solidified location will affect its cooling rate. Thirdly, this thin end at the bottom of wedge might not be cooled properly by the circulating cooling water due to stagnation. However, samples with the same cooling rate might have different amounts of microsegregation based on cooling and solidification conditions such as thickness of sample, coarsening, and homogenization period.

5.2. Microstructural Analysis. The microstructure of the three studied magnesium alloys was characterized by quantifying the area percentage of the secondary phases, average size of the secondary phase particles, the maximum size of the secondary phase particles, and the secondary dendrite arm spacing. All these microstructural features vary significantly with the change in cooling rate and subsequent microsegregation. The BSE micrographs were taken at 500x magnification 


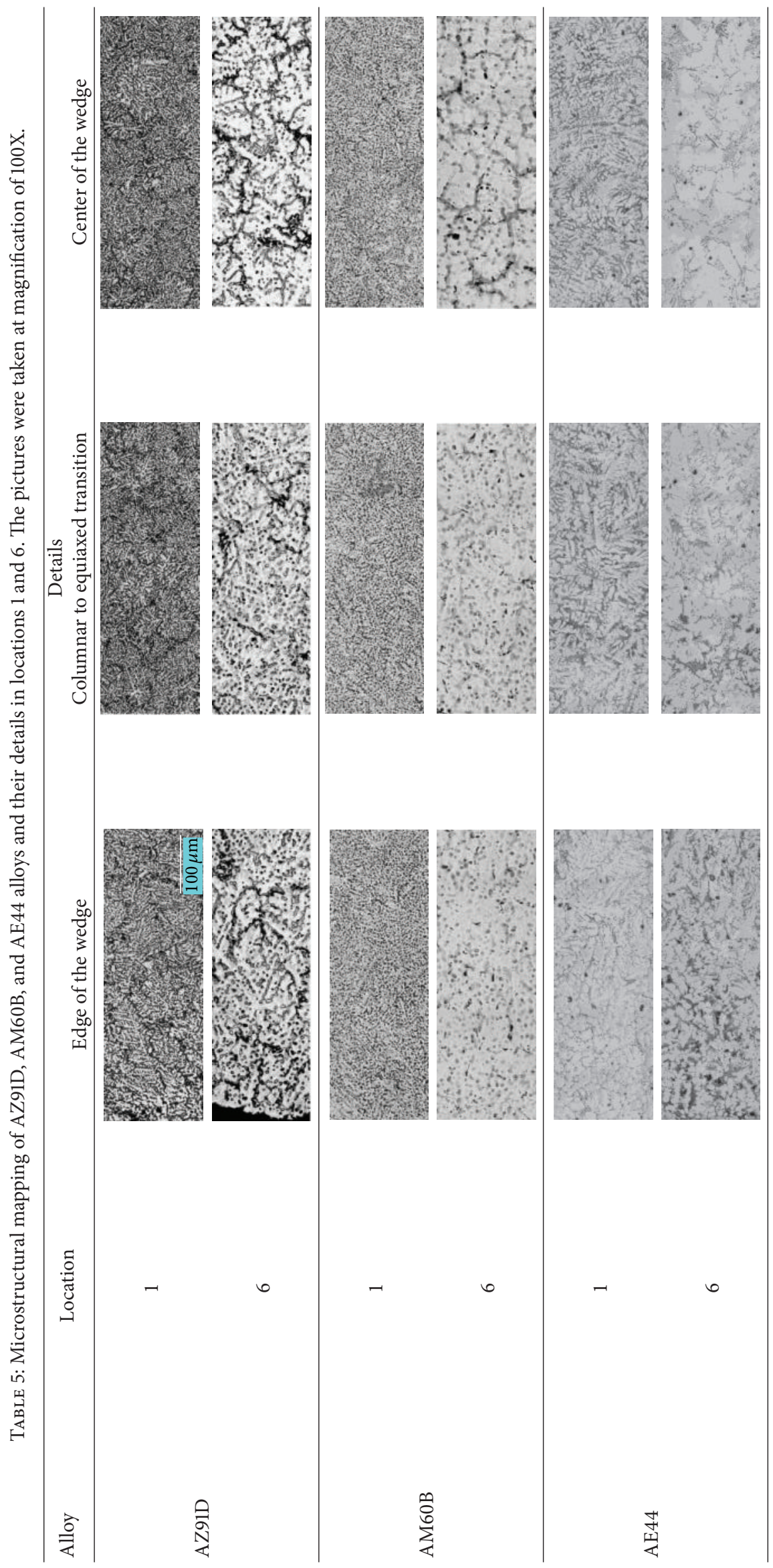




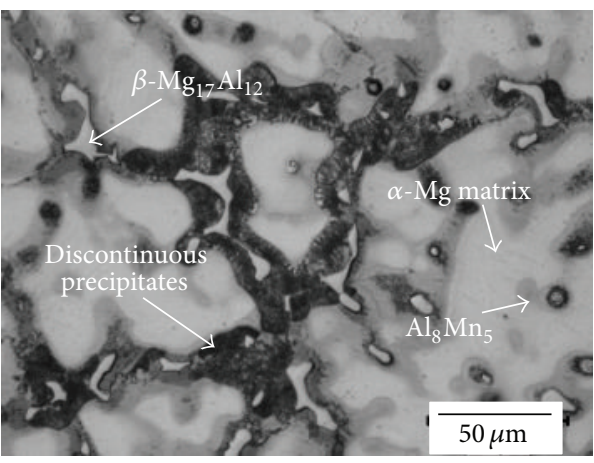

(a)

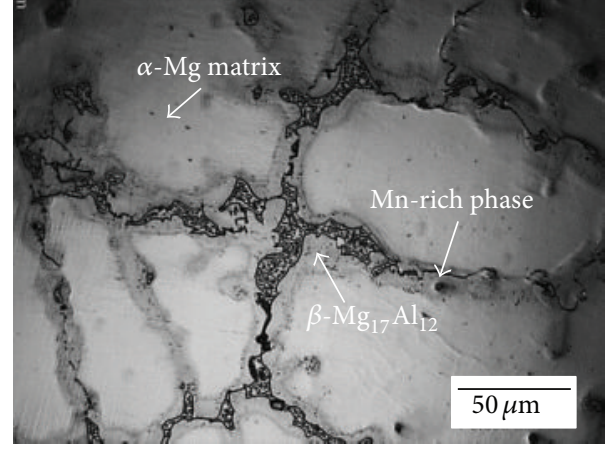

(b)

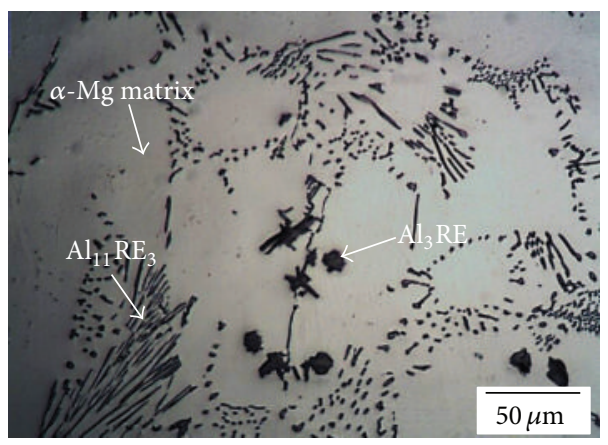

(c)

FIgURE 4: General microstructure of the as-cast (a) AZ91D alloy; (b) AM60B; (c) AE44, regardless of the thermocouple location.

for image analysis and each micrograph covers an area of $227 \mu \mathrm{m} \times 200 \mu \mathrm{m}$. Measurement of average and maximum size of secondary phase particles at specific locations provides information regarding overall particle size distribution.

Microstructural mapping was done from edge to edge for the first four thermocouple positions. For locations 5 and 6 , as they are much wider, pictures were taken from the center to the edge of the wedge instead of the regular patterned edge to edge. Microstructural maps and important segments are shown in Table 5. For each location of the wedge, these merged micrographic maps are divided into three sections: edge, transition from columnar to equiaxed, and midposition of the wedge.

The general microstructure of the as-cast $\mathrm{Mg}$ alloys is demonstrated in Figure 4. AZ91D alloy is characterized by a solid solution of aluminum in magnesium, which is known as $\alpha-\mathrm{Mg}$ (hexagonal close packed structure) and eutectic $\beta$ $\mathrm{Mg}_{17} \mathrm{Al}_{12}$ phase. Dendrite arms of $\alpha-\mathrm{Mg}$ are surrounded by a eutectic mixture of $\alpha$ and $\beta-\mathrm{Mg}_{17} \mathrm{Al}_{12}$. In addition to this, a small amount of $\mathrm{Al}_{8} \mathrm{Mn}_{5}$ is also noticed within the $\alpha$ Mg matrix. These phases are shown in Figure 4(a). The $\beta$ $\mathrm{Mg}_{17} \mathrm{Al}_{12}$ phase may be fully or partially divorced depending on the solidification rate. The typical microstructure of AM60B alloy that consisted of $\alpha-\mathrm{Mg}$ dendrite cells and a divorced-eutectic $\left(\alpha-\mathrm{Mg}+\beta-\mathrm{Mg}_{17} \mathrm{Al}_{12}\right)$ is presented in Figure 4(b). A few spherical Mn-rich intermetallic particles are also generally observed in the microstructure. The primary $\alpha-\mathrm{Mg}$ dendrites that form the largest portion of the microstructure are surrounded by divorced eutectic. A typical microstructure of AE44 alloy that consisted of primary $\alpha-\mathrm{Mg}$ dendrites and intermetallic phases in the interdendritic regions or at grain boundaries is presented in Figure 4(c).

The intermetallic phases have two distinctive morphologies; one is a lamellar or needle-like acicular morphology and the other is of a particulate or globular shape. The lamellar phase is identified as $\mathrm{Al}_{11} \mathrm{RE}_{3}$ and the particulate shaped particles are $\mathrm{Al}_{3} \mathrm{RE} . \mathrm{Al}_{11} \mathrm{RE}_{3}$ is the dominant phase in all wedge locations; the presence of $\mathrm{Al}_{3} \mathrm{RE}$ is in very small amounts.

Figure 5 shows SEM micrographs of the midpositions of the wedge at locations 1 and 6 of the three Mg alloys.

For AZ91D alloy, the size of the secondary phase particles increases significantly from location 1 to location 6 . Although the sizes of the particles are much smaller in location 1 , their number is much greater in comparison to location 6 . The distance between eutectic $\beta-\mathrm{Mg}_{17} \mathrm{Al}_{12}$ phase particles also increases with the decrease of cooling rate, which indicates that secondary dendrite arm spacing is varying with cooling rate. For $\mathrm{AM} 60 \mathrm{~B}$, a fully divorced morphology was observed for the $\beta-\mathrm{Mg}_{17} \mathrm{Al}_{12}$ phase in all locations. The presence of coring was more obvious in locations 5 and 6 . The size of individual secondary phase particles increased significantly from location 1 to location 6 , and subsequently the number of these particles decreased. For AE44 alloy, locations 1,2 , and 3 have a similar cluster-like morphology of $\mathrm{Al}_{11} \mathrm{RE}_{3}$. Then from location 4 the space between the clusters starts to increase. This transition continues in locations 5 and 6 , where the morphology shows scattered clusters. 

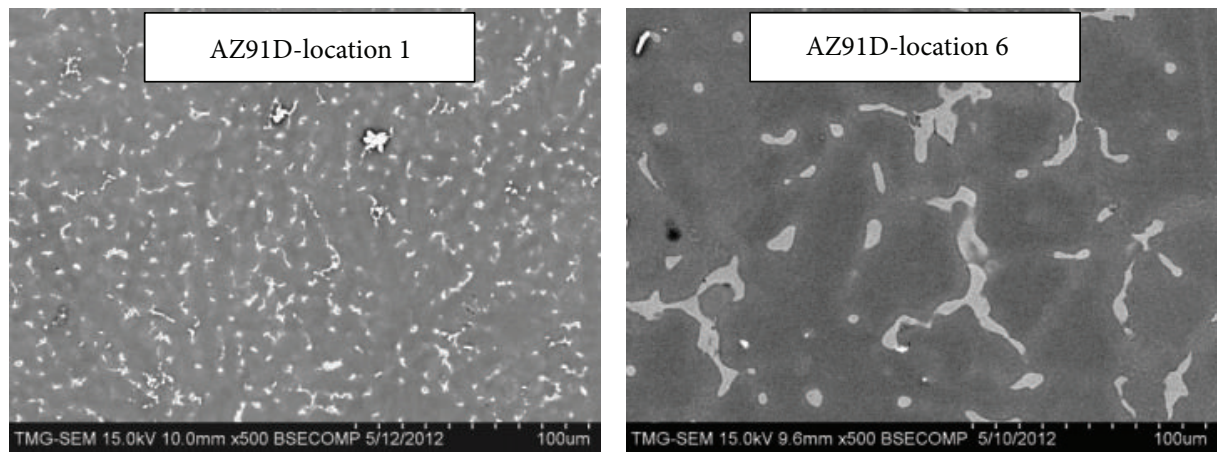

(a)
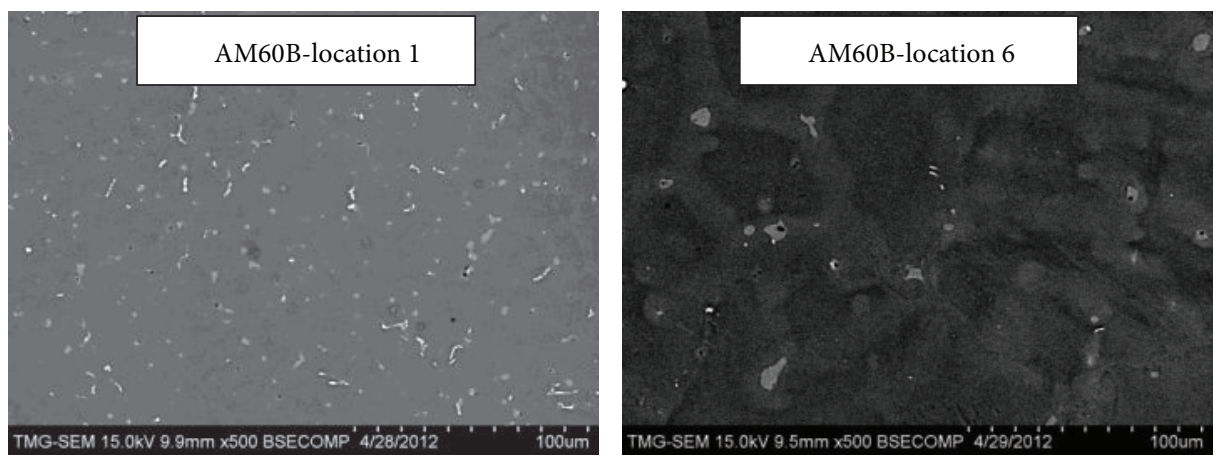

(b)
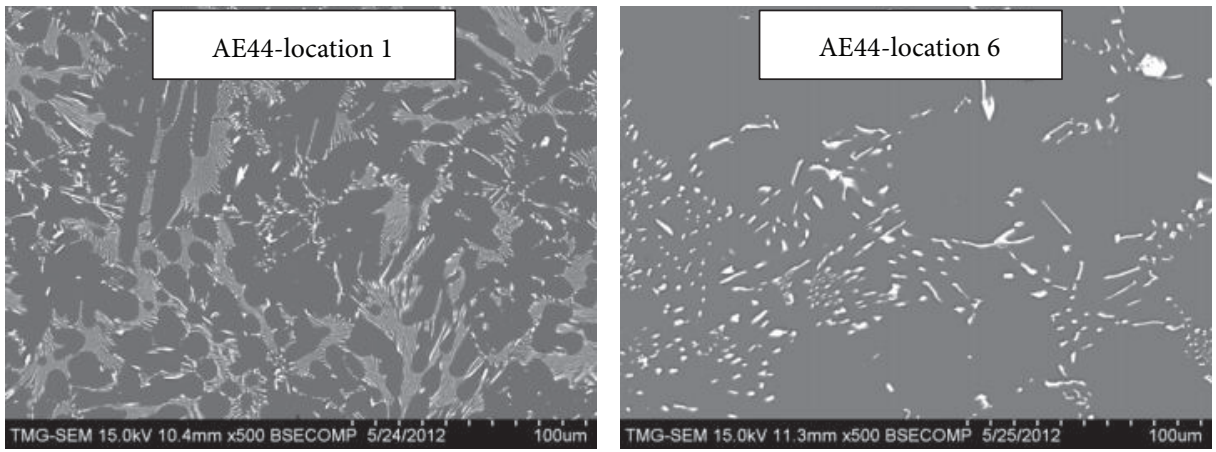

(c)

FIgURE 5: Microstructures at the midposition of the wedge at locations 1 and 6 for AZ91D, AM60B, and AE44 alloys.

The variation in secondary dendrite arm spacing (SDAS) measured close to the six thermocouple locations for the three Mg alloys is shown in Figures 6(a)-6(c). The variation of SDAS with the change of cooling rate for the three $\mathrm{Mg}$ alloys was calculated. It is concluded that the secondary dendrite arm spacing increases as the cooling rate decreases, from around $9 \mu \mathrm{m}$ at location 1 up to about $26 \mu \mathrm{m}$ at location 6, for AZ91D alloy. For AM60B alloy, the SDAS increased gradually with the decrease in cooling rate, from $15 \mu \mathrm{m}$ at location 1 up to $30 \mu \mathrm{m}$ at location 6 . The SDAS variation, for AE44, was in the range of $10-15 \mu \mathrm{m}$ at location 1 and increased up to $45 \mu \mathrm{m}$ at location 6 , due to significant reduction in cooling rate.

5.3. Microsegregation Measurements. Quantitative microsegregation analysis was carried out close to the six thermocouple locations for the three investigated magnesium alloys.
The following results were obtained from the acquired data at different locations of the wedge: solute redistribution profile for alloying elements (experimental and modeling), partition coefficient, segregation index (ratio between minima and bulk composition) and segregation deviation parameter $\left(\sigma_{m}\right)$, and area percentage of eutectic from the distribution profiles. Inhomogeneous distribution of solute elements during dendritic solidification of an alloy takes place due to coring. Coring or layered structure solidification is the key concept for understanding microsegregation. As can be seen from the schematic diagram of a dendrite arm in Figure 7(a), the chemical composition at point " $\mathrm{C}$ " is different from the chemical composition of point "E." It is assumed that solidification starts at point " $\mathrm{C}$ " and finishes at point " $\mathrm{E}$ " and the change in chemical composition is gradual. In Figure 7(b), the optical micrograph of AZ91D alloy is presented to be compared with the schematic diagram. 


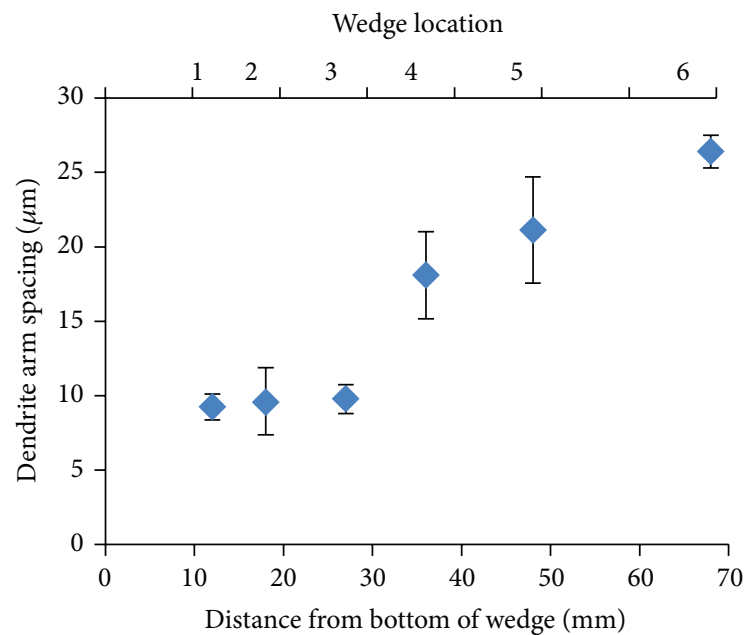

(a)

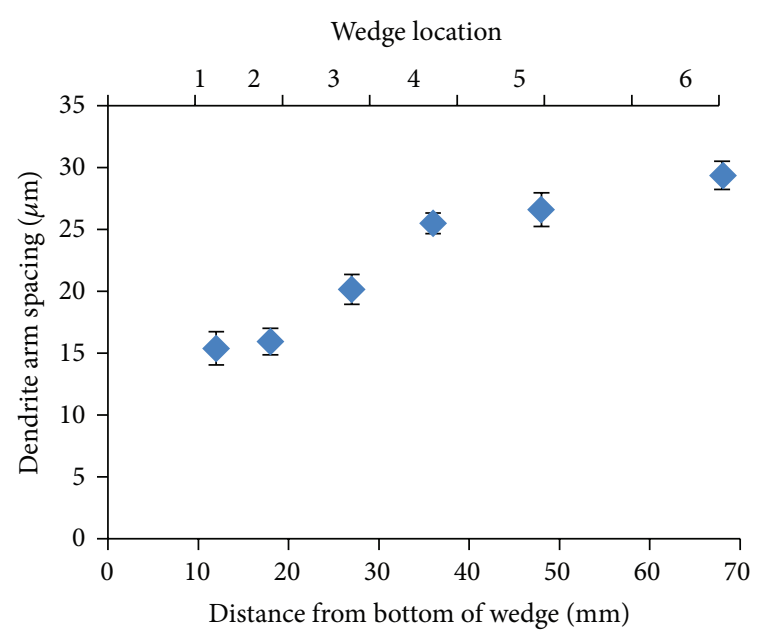

(b)

Wedge location

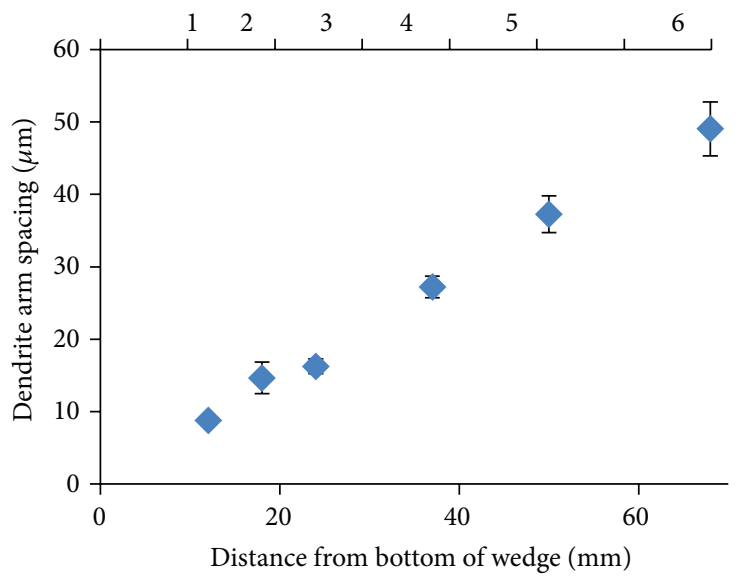

(c)

FIGURE 6: Secondary dendritic arm spacing measured at center of the wedge of (a) AZ91D; (b) AM60B; (c) AE44 at different locations.

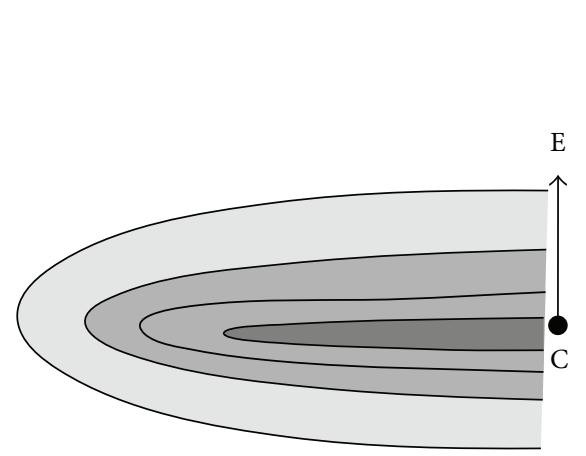

(a)

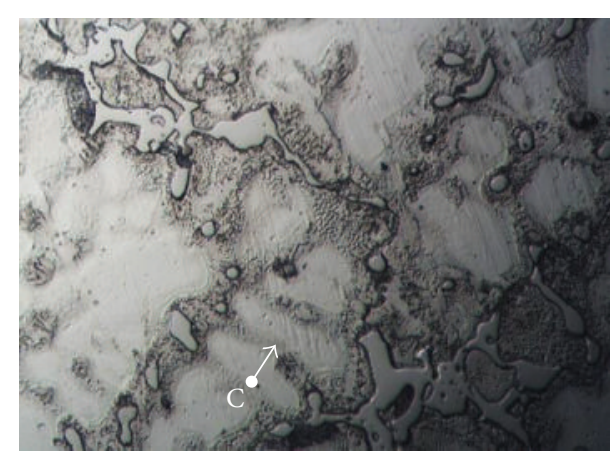

(b)

FIGURE 7: Coring in dendritic solidification; (a) schematic of dendrite arm and (b) dendritic microstructure in optical micrograph of AZ91D alloy. 


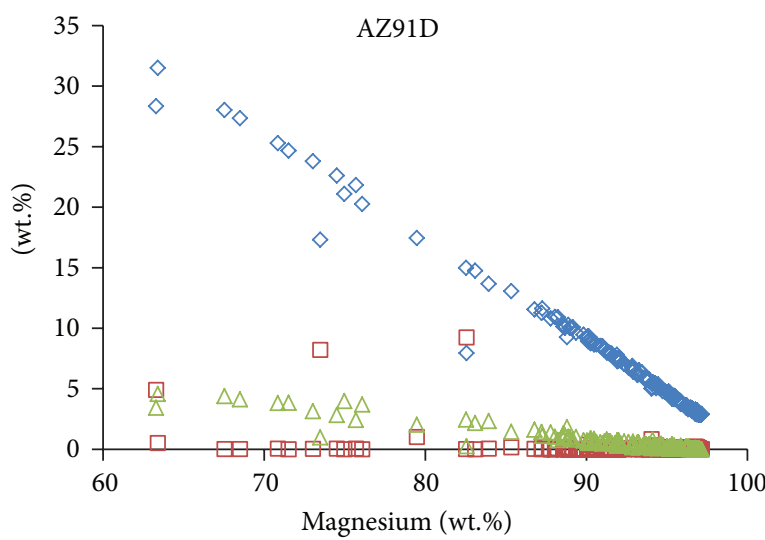

$\diamond \mathrm{Al}$

$\square \mathrm{Mn}$

$\triangle \mathrm{Zn}$

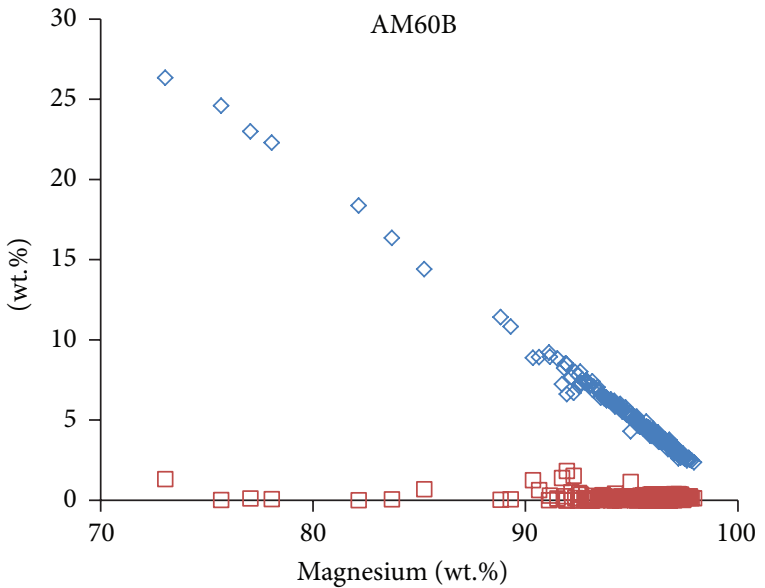

$\diamond \mathrm{Al}$

$\square \mathrm{Mn}$

(a)

(b)

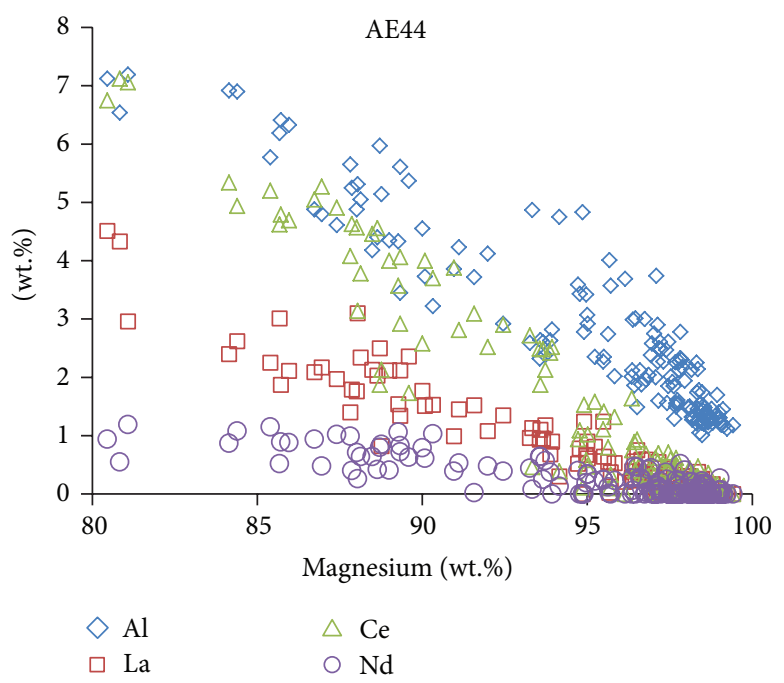

(c)

FIGURE 8: Segregation trend in investigated alloys.

When the molten alloy starts to solidify at point " $\mathrm{C}$," the wt.\% of aluminum can be as low as 2 or $3 \mathrm{wt} . \%$, depending on the cooling rate. And it gradually increases to the last point to be solidified, namely, point "E." Some alloying elements have a tendency to accumulate in higher concentration at the edge of the dendritic arm. These elements have low concentration at the center of the arm. Some alloying elements behave in the opposite way; they have higher concentration at the middle of dendrite arm and then gradually decrease towards the edge. This was mainly reported for the elements forming peritectic systems.

5.3.1. Solute Redistribution. In this work, microsegregation measurements were performed using SEM/EDS. 150 readings were taken in a $10 \times 15$ regular grid, with a spacing of $10 \mu \mathrm{m}$ between each point. All the data points were sorted based on the weighted interval ranking sort (WIRS) method [31]. The alloying elements which were present in less than $0.5 \mathrm{wt} . \%$ in the bulk composition of the alloy were neglected, because they are below the EDS detection limit. This could be the major source of the experimental errors, which lead to provision of different values of the calculated parameters. In this work, the microsegregation analysis was carried out for aluminum and zinc in AZ91D; aluminum and manganese in AM60B; and aluminum, cerium, and lanthanum in AE44. The segregation trend of these alloys for all locations in the casting is presented in Figure 8.

For AZ91D and AM60B, with the increase of magnesium concentration, the concentration of $\mathrm{Al}$ and $\mathrm{Zn}$ decreases, while $\mathrm{Mn}$ shows the opposite trend. This means that $\mathrm{Al}$ and $\mathrm{Zn}$ would be low in the dendrite core and gradually increase towards the dendrite periphery. For AE44 alloy, with the increase of $\mathrm{Mg}$ concentration, all other elements $\mathrm{Al}, \mathrm{La}, \mathrm{Ce}$, 


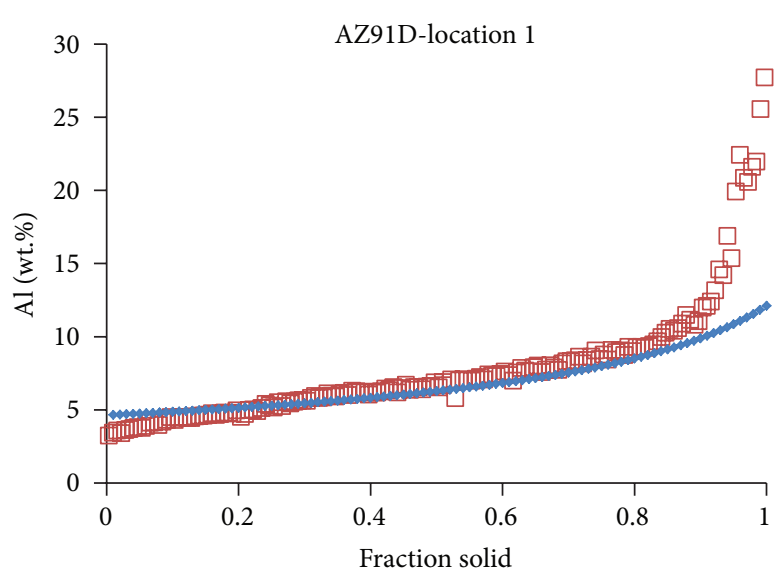

(a)

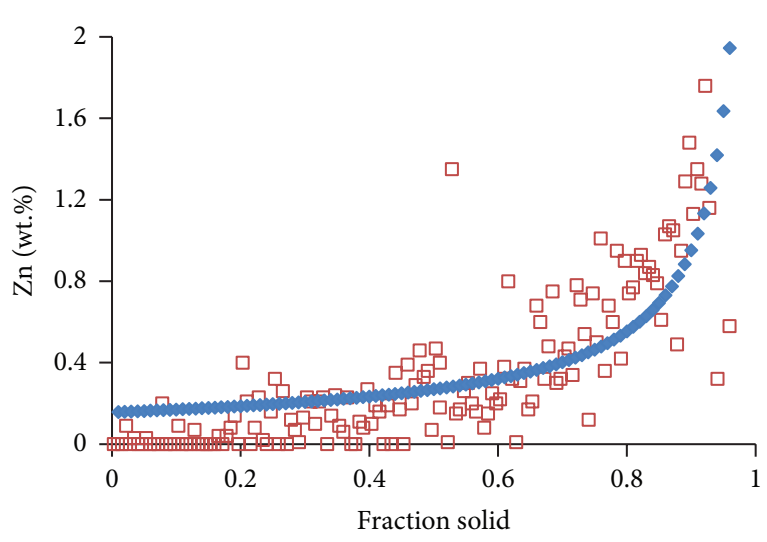

(c)

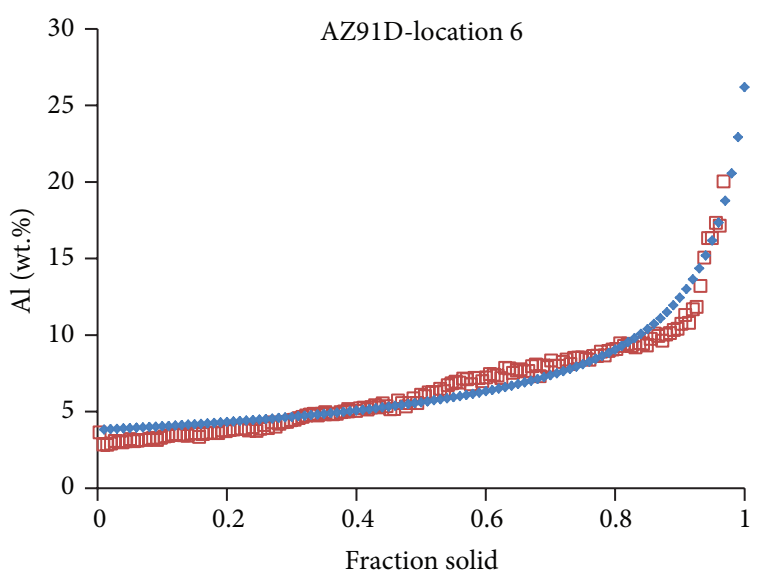

(b)

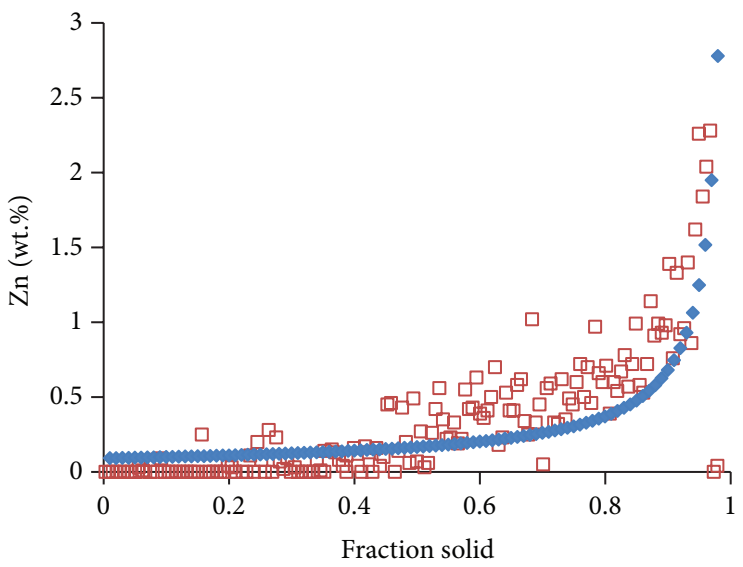

(d)

FIGURE 9: Solute redistribution in locations 1 and 6 of AZ91D alloy.

and $\mathrm{Nd}$ decrease in concentration. Thus, the concentration of these elements will be low in the dendrite core.

The Brody-Fleming equation [35] was used for modeling the solute redistribution profile modeling.

The parameters needed to calculate the solute profiles (composition at any specific point solidified $C_{S}$ ) using this model are dimensionless parameter $\alpha$, solid fraction $f_{S}$, partition coefficient $K$, and bulk composition $C_{0}$. The secondary dendrite arm spacing and solidification time at each location were used from the experimental data to calculate $\alpha$. From the experimentally measured data sorted by the WIRS method, values of $C_{S}$ and $f_{S}$ can be obtained. Putting these values in the Scheil equation (2), values of the partition coefficient $K$ were calculated.

The average value of $K$ was then used in the BrodyFleming model for drawing solute redistribution profiles for the three $\mathrm{Mg}$ alloys in all locations. These experimentally obtained values of $K$ for all major alloying elements are listed in Table 6. From the table, it is clear that the average value of the partition coefficient decreases with the decrease of cooling rate.

The solute redistribution profiles at locations 1 and 6 , for the major alloying elements of AZ91D, AM60B, and AE44, are shown in Figures 9, 10, and 11, respectively. Open symbols represent the solute profile obtained from the experimental data sorted and treated by the WIRS method and the closed symbols represent the curves calculated using the BrodyFleming model [35].

For AZ91D, the average value of $K_{\mathrm{Al}}$ is 0.53 at location 1 and 0.43 at location 6. However, Shang et al. [48] reported $K_{\mathrm{Al}}=0.35$ and $K_{\mathrm{Zn}}=0.09$ for the Scheil and equilibrium cooling. They also reported that for the Scheil cooling conditions, the partition coefficient remains constant up to 0.85 fractions solid. For AM60B, the average value of $K_{\mathrm{Al}}$ is 0.56 at location 1 and 0.41 at location 6 . Although in many solute redistribution models the partition coefficient value is considered to be the same for the Scheil and equilibrium cooling conditions, the results obtained from these experiments indicate that partition coefficient value changes significantly with cooling rate.

For AE44, the average value of $K_{\mathrm{Al}}$ at location 1 is 0.34 and at location 6 it decreases to 0.23 . For $\mathrm{Ce}$ and $\mathrm{La}$, the partition coefficient is too small, which could be due to their low solubility in $\mathrm{Mg}$. For $\mathrm{Ce}$, at location 1 the average $K$ is 0.068 and at location 6 it is 0.0257 . For La, at location 1 the average is 0.075 and at location 6 the average is 0.0283 . 


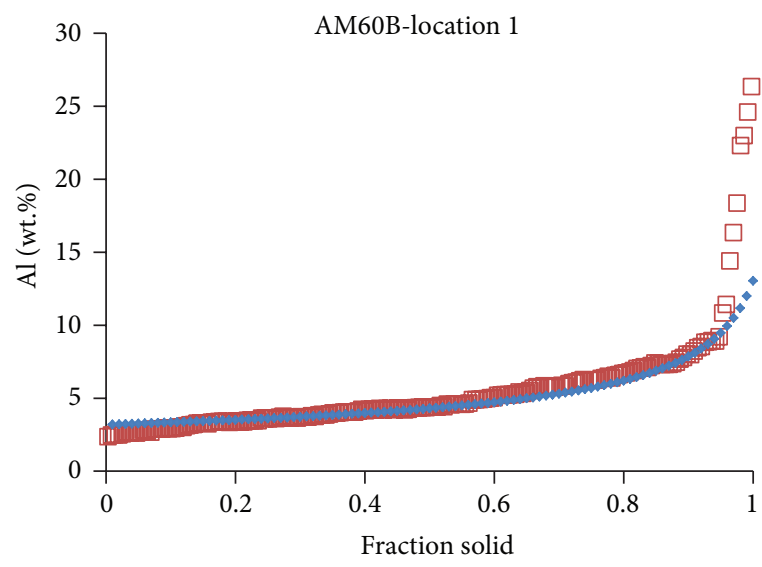

(a)

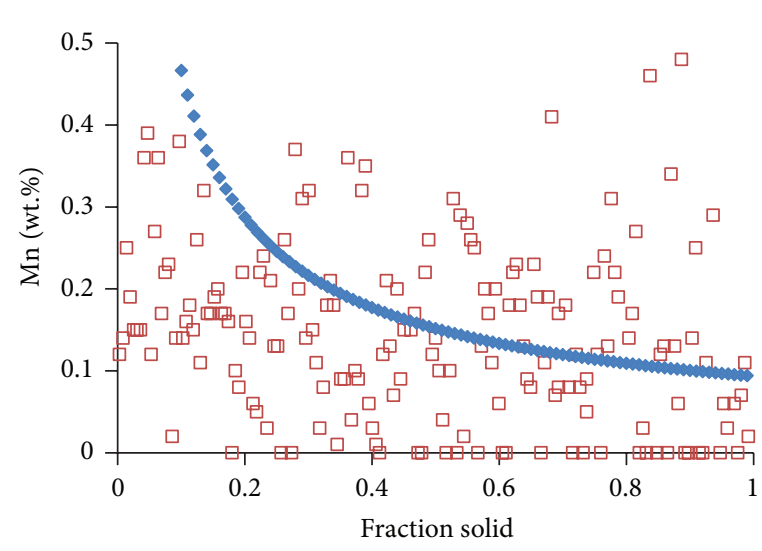

(c)

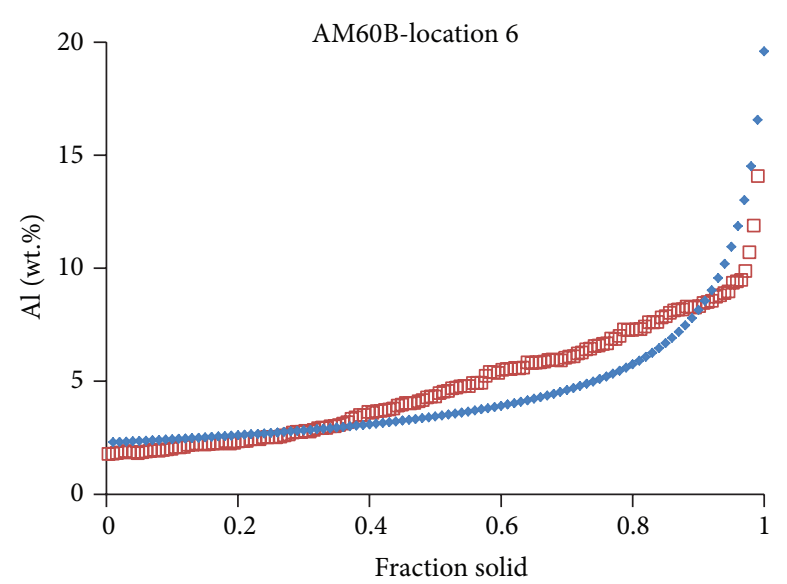

(b)

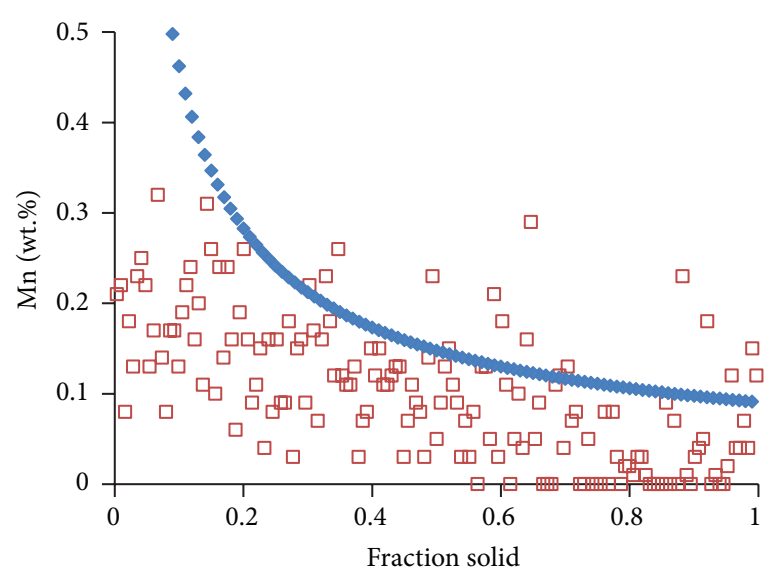

(d)

Figure 10: Solute redistribution in locations 1 and 6 of AM60B alloy.

Chia et al. [49] reported the partition coefficient for $\mathrm{La}$ and $\mathrm{Ce}$, using the binary phase diagrams of $\mathrm{Mg}-\mathrm{Ce}$ and $\mathrm{Mg}-\mathrm{La}$, as 0.0193 and 0.036 , respectively. Their partition coefficient values were closer to what has been obtained in slower cooling locations in this work. For both $\mathrm{Ce}$ and $\mathrm{La}$, at location 6 the partition coefficient is 0.03 .

5.3.2. Area Percentage Calculations of Secondary Phases. According to the $\mathrm{Mg}$-Al binary phase diagram, the maximum solubility of $\mathrm{Al}$ in $\mathrm{Mg}$ is around $12.9 \mathrm{wt} . \%$. On the basis of this assumption, the area fraction of $\beta-\mathrm{Mg}_{17} \mathrm{Al}_{12}$ phase was measured using the solute redistribution curve of aluminum at different wedge locations for AZ91D and AM60B alloys. In this method, a horizontal line is extended from the maximum $\mathrm{Al}$ solubility value. A vertical line is constructed at the end of the linear proportion of the fraction solid curve. The amount of the eutectic, then, can be calculated based on the difference between the fraction solid curve and the constructed vertical line. The procedure applied for these calculations is presented in Figure 12.

The eutectic area percentage was obtained through image analysis and the solute redistribution curve of aluminum for the three $\mathrm{Mg}$ alloys. In this work, $\beta-\mathrm{Mg}_{17} \mathrm{Al}_{12}$ is considered the eutectic phase in the AZ91D and AM60B alloys. No eutectic phase was formed in the AE44 alloy, and thus both $\mathrm{Al}_{3} \mathrm{RE}$ and $\mathrm{Al}_{11} \mathrm{RE}_{3}$ were the so-called secondary precipitates. Hence, for the three alloys, the $\alpha$-Mg matrix was considered the primary phase and all other particles were called the secondary phase. The area percent distribution of secondary phases measured from the solute redistribution curve and image analysis are available in Table 7. Accordingly, the eutectic area percentage of AZ91D alloy increases with cooling rate up to location 4 and then decreases at locations 5 and 6 . This trend is similar to observation by image analysis. For AM60B, at sample locations 1,2 , and 3, the area fraction was in the range of $3.5-5 \%$. Afterwards, a reduction was observed at locations 5 and 6 . At location 6 it was only $2 \%$.

In $\mathrm{AE} 44$, the composition of $\mathrm{Al}$ is very low in $\alpha-\mathrm{Mg}$ matrix as most of the aluminum reacts with the rare earth elements to form precipitates. Solubility of $\mathrm{La}, \mathrm{Ce}$, and $\mathrm{Nd}$ is also very low in the matrix. Hence the maximum solid solubility of $\mathrm{La}$ in $\mathrm{Mg} 0.8 \mathrm{wt}$ \% was assumed as the beginning of precipitate formation. For AE44 alloy, area percentage of secondary precipitates decreases gradually with cooling rate from $30 \%$ at location 1 to $8 \%$ at location 6 . Hehmann et al. [50] reported that the solid solubility of $\mathrm{Al}, \mathrm{La}$, and $\mathrm{Ce}$ in 


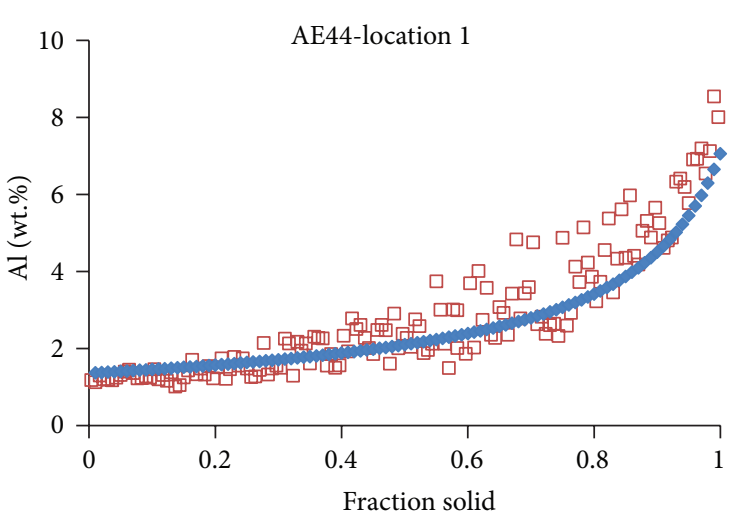

(a)

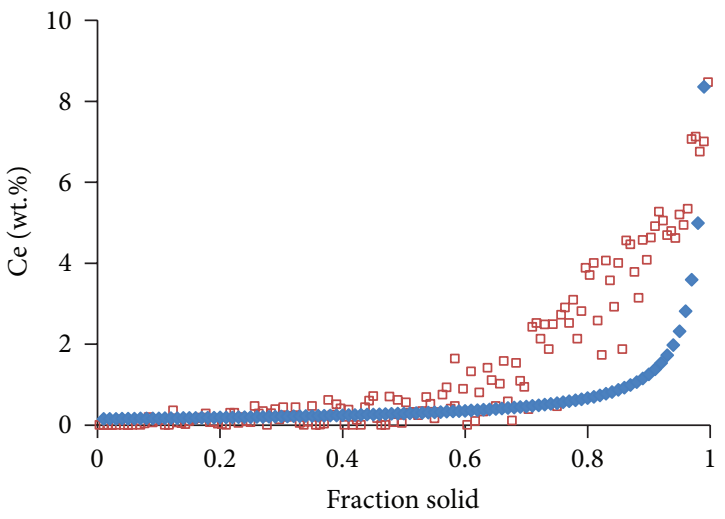

(c)

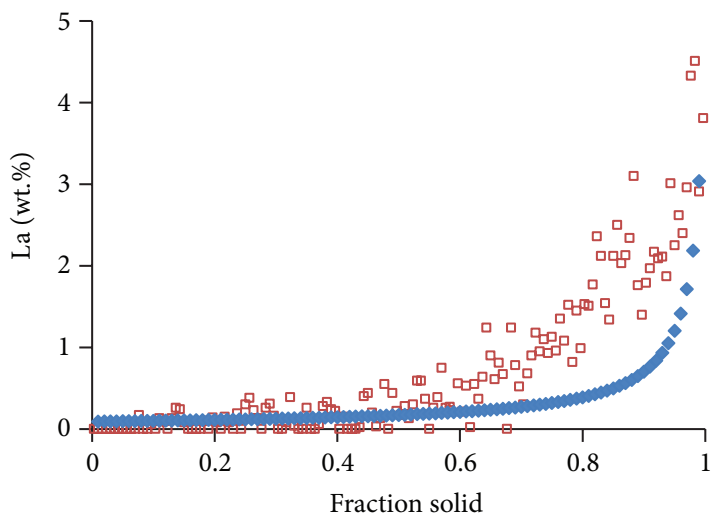

(e)

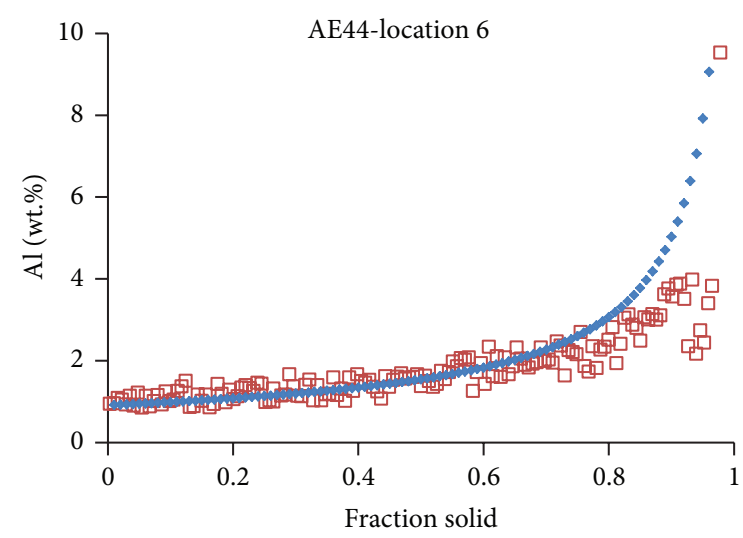

(b)

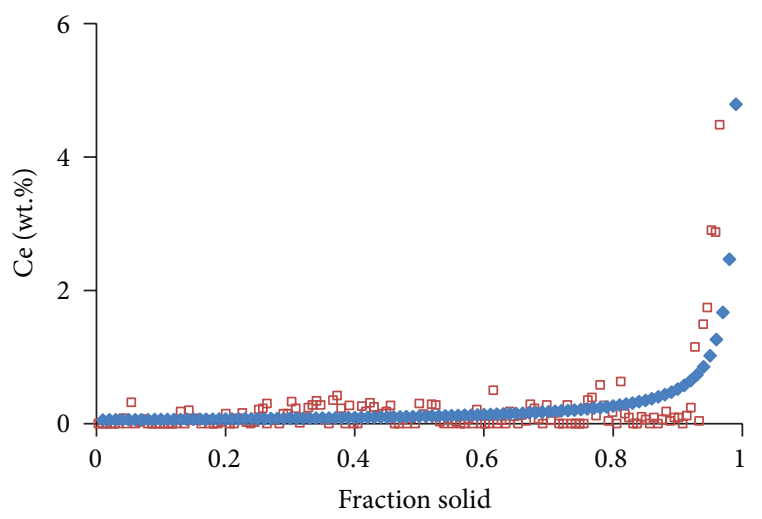

(d)

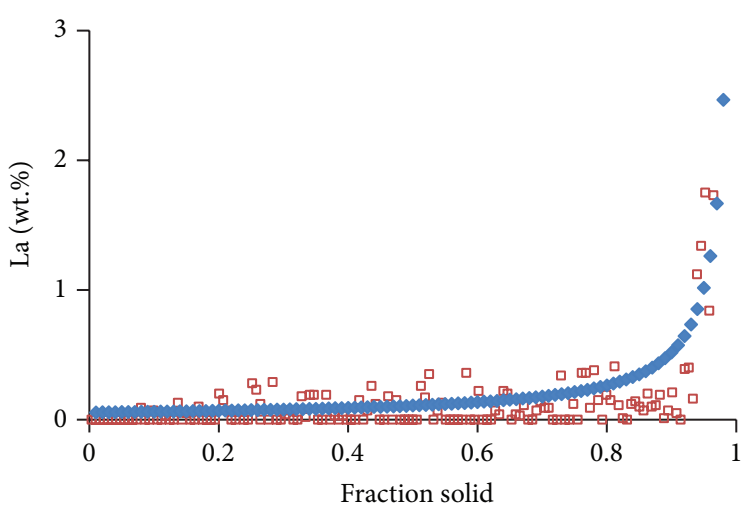

(f)

FIGURE 11: Solute redistribution in locations 1 and 6 of AE44 alloy.

$\mathrm{Mg}$ could be increased by rapid solidification method. Hence increased solid solubility in $\alpha$-Mg matrix will result in lower area percentage of eutectic phases. In the present experiment, very high cooling rate was observed at locations close to bottom of the wedge; therefore, it could affect the maximum solid solubility of other alloying elements in magnesium. This means that if accurate values of solid solubility are used to calculate the area percentage, the difference between image analysis and the solute distribution curve method may become less.
5.3.3. Segregation Index and Minimum Composition. The segregation index is the ratio between the minimum composition and bulk composition of an alloying element. To determine the minimum at a specific location, the average of the ten lowest compositions was taken. The minimum concentration of aluminum and the segregation index at different wedge locations for the three alloys are presented in Table 8. From the table, it can be seen that as the cooling rate decreases the minimum composition decreases and hence the severity of segregation increases. For AZ91D, the minimum 
TABLE 6: Effective partition coefficient for major alloying elements in the investigated alloys.

\begin{tabular}{|c|c|c|c|c|c|c|c|}
\hline \multirow{2}{*}{ Location } & \multicolumn{2}{|c|}{ AZ91D } & \multicolumn{2}{|c|}{ AM60B } & \multicolumn{3}{|c|}{$\mathrm{AE} 44$} \\
\hline & $K_{\mathrm{Al}}$ & $K_{\mathrm{Zn}}$ & $K_{\mathrm{Al}}$ & $K_{\mathrm{Mn}}$ & $K_{\mathrm{Al}}$ & $K_{\mathrm{Ce}}$ & $K_{\mathrm{La}}$ \\
\hline \multicolumn{8}{|l|}{1} \\
\hline Lowest & 0.42 & 0.04 & 0.48 & 0.03 & 0.29 & 0.02 & 0.02 \\
\hline Highest & 0.58 & 0.50 & 0.68 & 0.73 & 0.42 & 0.14 & 0.15 \\
\hline Average & 0.53 & 0.21 & 0.56 & 0.30 & 0.34 & 0.07 & 0.08 \\
\hline \multicolumn{8}{|l|}{2} \\
\hline Lowest & 0.42 & 0.03 & 0.39 & 0.01 & 0.17 & 0.02 & 0.00 \\
\hline Highest & 0.63 & 0.40 & 0.49 & 0.57 & 0.40 & 0.18 & 0.22 \\
\hline Average & 0.51 & 0.15 & 0.46 & 0.33 & 0.30 & 0.06 & 0.05 \\
\hline \multicolumn{8}{|l|}{3} \\
\hline Lowest & 0.44 & 0.08 & 0.36 & 0.03 & 0.31 & 0.02 & 0.02 \\
\hline Highest & 0.70 & 0.40 & 0.60 & 0.52 & 0.54 & 0.10 & 0.10 \\
\hline Average & 0.57 & 0.19 & 0.45 & 0.29 & 0.40 & 0.05 & 0.05 \\
\hline \multicolumn{8}{|l|}{4} \\
\hline Lowest & 0.32 & 0.06 & 0.30 & 0.01 & 0.21 & 0.01 & 0.01 \\
\hline Highest & 0.56 & 0.36 & 0.47 & 0.23 & 0.33 & 0.13 & 0.07 \\
\hline Average & 0.41 & 0.18 & 0.36 & 0.11 & 0.27 & 0.03 & 0.04 \\
\hline \multicolumn{8}{|l|}{5} \\
\hline Lowest & 0.29 & 0.01 & 0.35 & 0.02 & 0.29 & 0.01 & 0.01 \\
\hline Highest & 0.44 & 0.25 & 0.51 & 0.54 & 0.36 & 0.07 & 0.08 \\
\hline Average & 0.39 & 0.10 & 0.40 & 0.28 & 0.33 & 0.03 & 0.03 \\
\hline \multicolumn{8}{|l|}{6} \\
\hline Lowest & 0.33 & 0.03 & 0.31 & 0.01 & 0.19 & 0.01 & 0.02 \\
\hline Highest & 0.56 & 0.29 & 0.55 & 0.62 & 0.25 & 0.05 & 0.05 \\
\hline Average & 0.43 & 0.12 & 0.41 & 0.29 & 0.23 & 0.03 & 0.03 \\
\hline
\end{tabular}

${ }^{* *}$ Using FactSage software: $K_{\mathrm{Al}}=0.35, K_{\mathrm{Zn}}=0.09, K_{\mathrm{Ce}}=0.0193, K_{\mathrm{La}}=0.036$, and $K_{\mathrm{Mn}}=1.10$.

TABLE 7: Area percentage of secondary phases measured from solute redistribution curve and image analysis for the investigated alloys.

\begin{tabular}{|c|c|c|c|c|c|c|}
\hline \multirow{2}{*}{ Location } & \multicolumn{2}{|c|}{ AZ91D } & \multicolumn{2}{|c|}{ AM60B } & \multicolumn{2}{|c|}{$\mathrm{AE} 44$} \\
\hline & Solute curve & Image analysis & Solute curve & Image analysis & Solute curve & Image analysis \\
\hline 1 & 7.5 & 5.5 & 3.4 & 1.6 & 30 & 20.8 \\
\hline 2 & 7.6 & 5.8 & 4.0 & 1.6 & 24 & 21.0 \\
\hline 3 & 8 & 6.5 & 5.0 & 2.1 & 22 & 17.8 \\
\hline 4 & 10 & 7.1 & 4.0 & 2.1 & 12 & 13.2 \\
\hline 5 & 7 & 6.5 & 2.7 & 1.9 & 12 & 9.2 \\
\hline 6 & 6.6 & 4.5 & 2.0 & 1.7 & 8 & 8.6 \\
\hline
\end{tabular}

concentration of aluminum decreases with the decrease of cooling rate. At location 1 , the composition is $3.6 \mathrm{wt} . \%$ and at location 6 it drops to 3.01 wt.\%. For AM60B, at location 1 , minimum concentration of aluminum is $2.5 \mathrm{wt} . \%$ and at location 6 it reduces to 1.8 wt.\%. For AE44, at location 1, the minimum concentration of aluminum is $1.1 \mathrm{wt} . \%$ and at locations 6 the concentration is 0.9 wt. $\%$.

5.3.4. Segregation Deviation. The severity of microsegregation is measured by the segregation deviation parameter $\left(\sigma_{m}\right)$ using (1). Martorano and Capocchi [29] reported that microsegregation severity is lower for columnar dendrites than for equiaxed ones. It has also been reported that the increase in segregation deviation parameter, $\sigma_{m}$, for a change in structure from columnar to equiaxed, seems to be constant, approximately 0.11 , for the $\mathrm{Cu}-8 \mathrm{wt}$.\% Sn alloys. However, this value can be applicable for any particular system, since it shows the difference in the amount of segregation between columnar and equiaxed segregation. Consequently, the type of dendritic growth seems to be an important variable to define microsegregation. The greater microsegregation severity observed in an equiaxed dendrite zone compared with that in columnar dendrites might be the result of more homogenization in the latter structure. The overall deviation from the bulk composition for aluminum is presented in Figure 13.

In the present work, location 1 could be considered as columnar dendritic and location 6 could be considered as 
TABLE 8: Minimum concentration of aluminum and segregation index for the investigated alloys at different locations.

\begin{tabular}{|c|c|c|c|c|c|c|}
\hline \multirow{2}{*}{ Location } & \multicolumn{2}{|c|}{ AZ91D } & \multicolumn{2}{|c|}{ AM60B } & \multicolumn{2}{|c|}{$\mathrm{AE} 44$} \\
\hline & Minimum Al & Segregation index & Minimum $\mathrm{Al}$ & Segregation index & Minimum $\mathrm{Al}$ & Segregation index \\
\hline 1 & 3.63 & 2.42 & 2.56 & 2.23 & 1.15 & 3.44 \\
\hline 2 & 3.57 & 2.47 & 2.25 & 2.54 & 1.21 & 3.27 \\
\hline 3 & 3.54 & 2.49 & 2.19 & 2.61 & 1.30 & 3.04 \\
\hline 4 & 2.90 & 3.03 & 1.89 & 3.01 & 1.06 & 3.73 \\
\hline 5 & 3.12 & 2.82 & 2.05 & 2.78 & 1.07 & 3.69 \\
\hline 6 & 3.01 & 2.93 & 1.84 & 3.10 & 0.90 & 4.39 \\
\hline
\end{tabular}

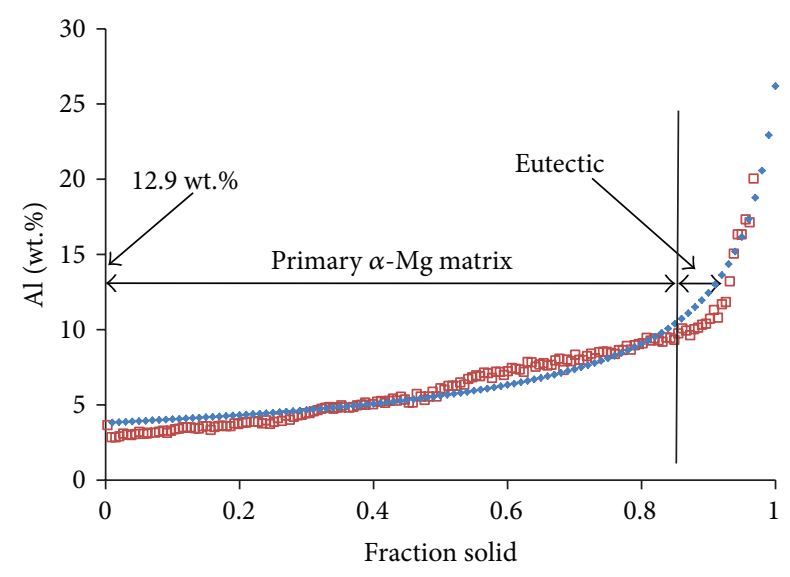

FIGURE 12: Procedure for the eutectic fraction calculation using the solute redistribution curve.

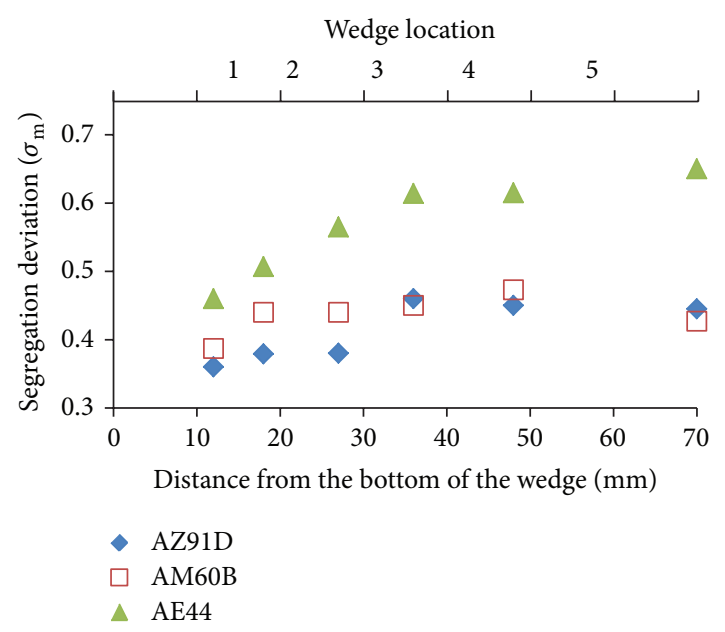

FIGURE 13: Segregation deviation for three investigated alloys.

equiaxed dendritic. The difference in deviation from location 1 to location 6 for AZ91D, AM60B, and AE44 is $0.08,0.06$, and 0.19 , respectively, which is comparable to the results observed by Martorano and Capocchi [29].

For AM60B alloy, from location 1 to location 5 the segregation deviation increases and then it slightly decreases at location 6, thus contradicting the segregation index. The segregation index is high at location 6 , but when the segregation deviation is calculated on a broader range, the segregation deviation is comparatively lower than at other locations.

\section{Summary}

Three main Mg alloys (AZ91D, AM60B, and AE44) solidified in a range of cooling rates $\left(1-20^{\circ} \mathrm{C} / \mathrm{min}\right)$ were studied and found to exhibit dendritic microstructures. At higher cooling rate (locations 1 and 2) the dendritic morphology was predominantly columnar and at lower cooling rate (locations 5 and 6) dendritic equiaxed morphology was observed. Secondary dendrite arm spacing increased significantly with the decrease of cooling rate for all three investigated alloys. The arm spacing ranges for the different alloys are 10 to $25 \mu \mathrm{m}$ for AZ91D, 15 to $30 \mu \mathrm{m}$ for AM60B, and 10 to $45 \mu \mathrm{m}$ for AE44. The average size of secondary phase particles increased substantially with the decrease of cooling rate. For AZ91D, the $\beta-\mathrm{Mg}_{17} \mathrm{Al}_{12}$ phase had a partially divorced morphology at fast cooled locations of the wedge and fully divorced morphology at slowly cooled locations. For AE44, the secondary precipitates had cluster-like morphology at faster cooling rate and gradually became more dispersed with slower cooling rate.

Microsegregation was more pronounced at slow cooled locations, which is evident from the microsegregation parameters. The minimum concentration of aluminum was always low for slow cooled locations ( 3 wt. \% at location 6 in comparison to $3.6 \mathrm{wt}$.\% at location 1 for AZ91D alloy). Significant difference in segregation deviation $\left(\Delta \sigma_{m}\right)$ was observed between the columnar and the equiaxed dendrites, approximately in the range of (0.06-0.19) for the three alloys. The higher segregation deviation observed in equiaxed morphology is probably due to prolonged back diffusion which takes place at slow cooling rates.

Experimentally obtained solute redistribution profiles match reasonably with theoretically calculated profiles except at very low solid fraction. This discrepancy at low solid fraction is possibly due to the presence of a few primary dendritic arms in the microstructure which have lower concentration of aluminum than the rest of the matrix. The elemental partition coefficients calculated from the experimentally obtained redistribution profiles were comparatively higher than the partition coefficients calculated from binary phase diagrams.

Area fraction of secondary phase particles measured by two different methods, image analysis and solute 
redistribution curves, showed close resemblance. Area fraction measured from solute redistribution curves is comparatively higher due to the fact that in case of image analysis only the secondary phase particles are measured based on color threshold, while in solute curve method regions adjacent to particles which have high concentration of alloying elements (e.g., eutectic phases) are also taken into account.

\section{Conflict of Interests}

The authors declare that there is no conflict of interests regarding the publication of this paper.

\section{Acknowledgment}

The authors would like to acknowledge AUTO21 NSERC Strategic Network of Excellence for the financial support of this work.

\section{References}

[1] A. Boby, U. Pillai, B. Pillai, and B. Pai, "Developments in magnesium alloys for transport applications-an overview," Indian Foundry Journal, vol. 57, p. 30, 2011.

[2] R. S. Beals, C. Tissington, X. Zhang et al., "Magnesium global development: outcomes from the TMS 2007 annual meeting," Journal of the Minerals, Metals and Materials Society, vol. 59, no. 8, pp. 39-42, 2007.

[3] G. Davies, Materials for Automobile Bodies, ButterworthHeinemann, Oxford, UK, 2003.

[4] H. Mao, V. Chandrasekar, M. Murray et al., "Microstructural characteristics of die cast AZ91D and AM60 magnesium alloys," Tech. Rep., SAE, 1996.

[5] E. Aghion, B. Bronfin, and D. Eliezer, "The role of the magnesium industry in protecting the environment," Journal of Materials Processing Technology, vol. 117, no. 3, pp. 381-385, 2001.

[6] J. Quaresma, C. Santos, and A. Garcia, "Correlation between unsteady-state solidification conditions, dendrite spacings, and mechanical properties of AI-Cu alloys," Metallurgical and Materials Transactions A, vol. 31, no. 12, pp. 3167-3178, 2000.

[7] X. Zheng, A. Luo, C. Zhang, J. Dong, and R. Waldo, "Directional solidification and microsegregation in a magnesiumaluminum-calcium alloy," Metallurgical and Materials Transactions A, vol. 43, no. 9, pp. 3239-3248, 2012.

[8] D. Mirković and R. Schmid-Fetzer, "Directional solidification of Mg-Al alloys and microsegregation study of Mg alloys AZ31 and AM50-part I: methodology," Metallurgical and Materials Transactions A, vol. 40, no. 4, pp. 958-973, 2009.

[9] D. Mirković and R. Schmid-Fetzer, "Directional solidification of $\mathrm{Mg}$-Al alloys and microsegregation study of Mg alloys AZ31 and AM50-part II: comparison between Az31 and AM50," Metallurgical and Materials Transactions A, vol. 40, no. 4, pp. 974-981, 2009.

[10] C. Zhang, D. Ma, K. S. Wu et al., "Microstructure and microsegregation in directionally solidified $\mathrm{Mg}-4 \mathrm{Al}$ alloy," Intermetallics, vol. 15, no. 10, pp. 1395-1400, 2007.

[11] A. Luo, "Understanding the solidification of magnesium alloys," in Proceedings of the 3rd International Magnesium Conference, pp. 449-464, Manchester, UK, 1997.
[12] D. H. Stjohn, A. K. Dahle, T. Abbott, M. D. Nave, and M. Qian, "Solidification of cast magnesium alloys," in Proceedings of the Minerals, Metals and Materials Society (TMS '03), pp. 95-100, Magnesium Technology, San Diego, Calif, USA, 2003.

[13] Y. W. Riddle and M. M. Makhlouf, "Characterizing solidification by non- equilibrium thermal analysis," in Proceedings of the Minerals, Metals and Materials Society (TMS '03), pp. 101-106, Magnesium Technology, San Diego, Calif, USA, 2003.

[14] A. Lindemann, J. Schmidt, M. Todte, and T. Zeuner, “Thermal analytical investigations of the magnesium alloys AM60 and AZ91 including the melting range," Thermochimica Acta, vol. 382, no. 1-2, pp. 269-275, 2002.

[15] M. Ohno, D. Mirkovic, and R. Schmid-Fetzer, "On liquidus and solidus temperatures in AZ and AM alloys," in Proceedings of the Minerals, Metals and Materials Society (TMS '06), pp. 129-132, San Antonio, Tex, USA, 2006.

[16] M. D. Nave, A. K. Dahle, and D. H. StJohn, "Eutectic growth morphologies in magnesium-aluminium alloys," in Proceedings of the Minerals, Metals and Materials Society (TMS '02), pp. 233242, Nashville, Tenn, USA, 2000.

[17] L. P. Barber, "Characterization of the solidification behavior and resultant microstructures of magnesium-aluminum alloys," in Materials Science and Engineering, Worcester Polytechnic Institute, Worcester, Mass, USA, 2004.

[18] A. K. Dahle, Y. C. Lee, M. D. Nave, P. L. Schaffer, and D. H. Stjohn, "Development of the as-cast microstructure in magnesium-aluminium alloys," Journal of Light Metals, vol. 1, no. 1, pp. 61-72, 2001.

[19] S. Barbagallo, H. Laukli, O. Lohne, and E. Cerri, "Divorced eutectic in a HPDC magnesium-aluminum alloy," Journal of Alloys and Compounds, vol. 378, no. 1-2, pp. 226-232, 2004.

[20] M. N. Khan, M. Aljarrah, J. T. Wood, and M. Medraj, “The effect of cooling rate on thermophysical properties of magnesium alloys," Journal of Materials Research, vol. 26, no. 8, pp. 974-982, 2011.

[21] L.-Y. Wei and R. Warren, "Microstructural characterisation of several magnesium alloys in AM series," Materials Science and Technology, vol. 23, no. 6, pp. 745-752, 2007.

[22] Q. Han, E. Kenik, S. Agnew, and S. Viswanathan, "Solidification behaviour of commercial magnesium alloys," in Magnesium Technology, pp. 81-86, The Minerals, Metals \& Materials Society, Warrendale, Pa, USA, 2001.

[23] Z. Zhang, A. Couture, R. Tremblay, and D. Dube, "Microstructure and mechanical properties of permanent mold and die casting of AZ 91 magnesium alloy," in Proceedings of the International Symposium on Light Metals, pp. 397-406, Canadian Institute of Mining Metallurgy and Petroleum, 1999.

[24] A. Ditze and K. Schwerdtfeger, "Strip casting of magnesium with the single-belt process," Scandinavian Journal of Metallurgy, vol. 32, no. 6, pp. 311-316, 2003.

[25] S. Guo, Q. Le, Y. Han, Z. Zhao, and J. Cui, "The effect of the electromagnetic vibration on the microstructure, segregation, and mechanical properties of As-cast AZ80 magnesium alloy billet," Metallurgical and Materials Transactions A, vol. 37, no. 12, pp. 3715-3724, 2006.

[26] M. Gungor, "A statistically significant experimental technique for investigating microsegregation in cast alloys," Metallurgical Transactions A, vol. 20, no. 11, pp. 2529-2533, 1989.

[27] J. Sarreal and G. Abbaschian, "The effect of solidification rate on microsegregation," Metallurgical Transactions A, vol. 17, no. 11, pp. 2063-2073, 1986. 
[28] M. C. Flemings, D. R. Poirier, R. V. Barone, and H. D. Brody, "Microsegregation in Iron base alloys," Journal of Iron and Steel Institute, vol. 208, pp. 371-381, 1970.

[29] M. Martorano and J. Capocchi, "Effects of processing variables on the microsegregation of directionally cast samples," Metallurgical and Materials Transactions A, vol. 31, no. 12, pp. 31373148, 2000.

[30] W. Yang, K.-M. Chang, W. Chen, S. Mannan, and J. Debarbadillo, "Monte carlo sampling for microsegregation measurements in cast structures," Metallurgical and Materials Transactions A, vol. 31, no. 10, pp. 2569-2574, 2000.

[31] M. Ganesan, D. Dye, and P. Lee, "A technique for characterizing microsegregation in multicomponent alloys and its application to single-crystal superalloy castings," Metallurgical and Materials Transactions A, vol. 36, no. 8, pp. 2191-2204, 2005.

[32] D. R. Poirier, Microsegregation in Ternary Iron-CarbonChromium Alloys, Department of Metallurgy, Massachusetts Institute of Technology, Cambridge, Mass, USA, 1966.

[33] E. Scheil, "Bemerkungen zur schichtkristallbildung," Zeitschrift Metallkunde, vol. 34, pp. 70-72, 1942.

[34] T. Clyne and W. Kurz, "Solute redistribution during solidification with rapid solid state diffusion," Metallurgical Transactions A, vol. 12, no. 6, pp. 965-971, 1981.

[35] T. Bower, H. Brody, and M. Flemings, "Measurements of solute redistribution in dendritic solidification," Transaction of the Metallurgical Society of AIME, vol. 236, pp. 624-633, 1966.

[36] I. Ohnaka, " Mathematical analysis of solute redistribution during solidification with diffusion in solid phase," Transactions of the Iron and Steel Institute of Japan, vol. 26, no. 12, pp. 1045$1051,1986$.

[37] S. Kobayashi, "A mathematical model for solute redistribution during dendritic solidification," Transactions of the Iron and Steel Institute of Japan, vol. 28, pp. 535-542, 1988.

[38] L. Nastac and D. M. Stefanescu, "An analytical model for solute redistribution during solidification of planar, columnar, or equiaxed morphology," Metallurgical Transactions A, vol. 24, no. 9, pp. 2107-2118, 1993.

[39] J. Lacaze, P. Benigni, and A. Howe, "Some issues concerning experiments and models for alloy microsegregation," Advanced Engineering Materials, vol. 5, no. 1-2, pp. 37-46, 2003.

[40] T. Kraft, M. Rettenmayr, and H. Exner, "An extended numerical procedure for predicting microstructure and microsegregation of multicomponent alloys," Modelling and Simulation in Materials Science and Engineering, vol. 4, no. 2, pp. 161-177, 1996.

[41] F. Y. Xie, T. Kraft, Y. Zuo, C. H. Moon, and Y. A. Chang, "Microstructure and microsegregation in Al-rich Al-Cu-Mg alloys," Acta Materialia, vol. 47, no. 2, pp. 489-500, 1999.

[42] Q. Du and A. Jacot, "A two-dimensional microsegregation model for the description of microstructure formation during solidification in multicomponent alloys: formulation and behaviour of the model," Acta Materialia, vol. 53, no. 12, pp. 3479-3493, 2005.

[43] W. J. Boettinger, U. R. Kattner, and D. K. Banerjee, "Analysis of solidification path and microsegregation in multicomponent alloys," in Modelling of Casting, Welding and Advanced Solidification Processed-VIII, B. G. Thomas and C. Beckermann, Eds., vol. 1, pp. 159-170, TMS, Warrendale, Pa, USA, 1998.

[44] M. C. Flemings, Solidification Processing, McGraw-Hill, 1974.

[45] M. C. Flemings, "Solidification processing," Metallurgical Transactions, vol. 5, no. 10, pp. 2121-2134, 1974.
[46] R. M. Kearsey, "Compositional effects on microsegregation behaviour in single crystal superalloy systems," in Mechanical and Aerospace Engineering, Carleton University, Ontario, Canada, 2004.

[47] H. Putz and K. Brandenburg, Pearson's Crystal Data, Crystal Structure Database for Inorganic Compounds.

[48] S. Shang, H. Zhang, S. Ganeshan, and Z.-K. Liu, "The development and application of a thermodynamic database for magnesium alloys," Journal of the Minerals, Metals and Materials Society, vol. 60, no. 12, pp. 45-47, 2008.

[49] T. L. Chia, M. A. Easton, S. M. Zhu, M. A. Gibson, N. Birbilis, and J. F. Nie, "The effect of alloy composition on the microstructure and tensile properties of binary Mg-rare earth alloys," Intermetallics, vol. 17, no. 7, pp. 481-490, 2009.

[50] F. Hehmann, F. Sommer, and B. Predel, "Extension of solid solubility in magnesium by rapid solidification," Materials Science and Engineering A, vol. 125, no. 2, pp. 249-265, 1990. 

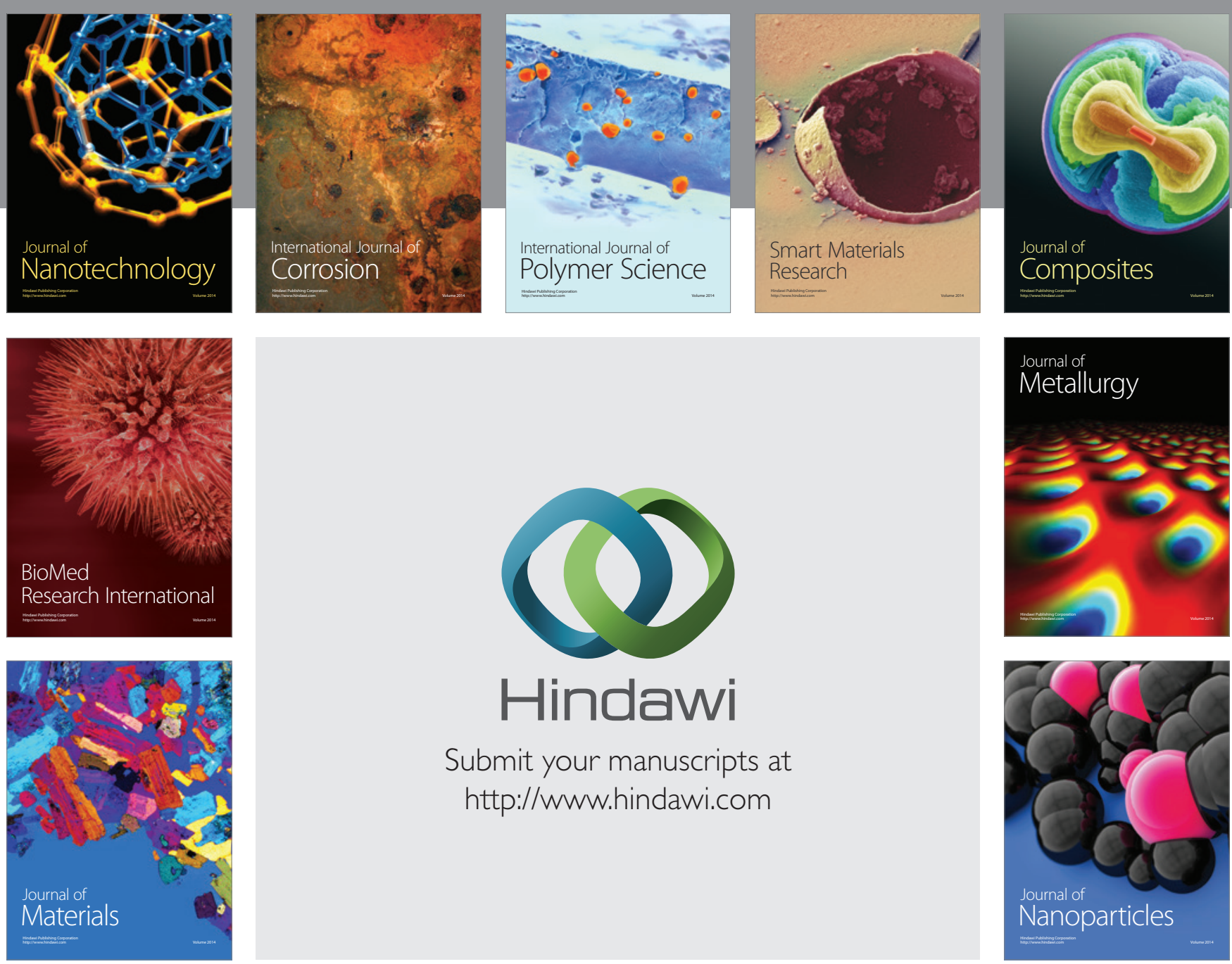

Submit your manuscripts at http://www.hindawi.com
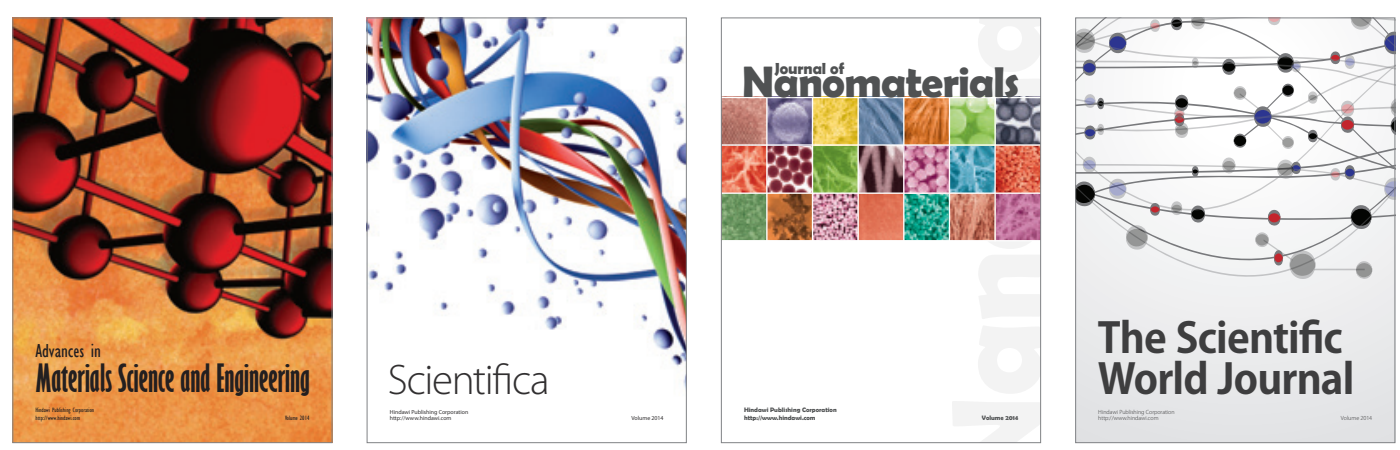

\section{The Scientific World Journal}
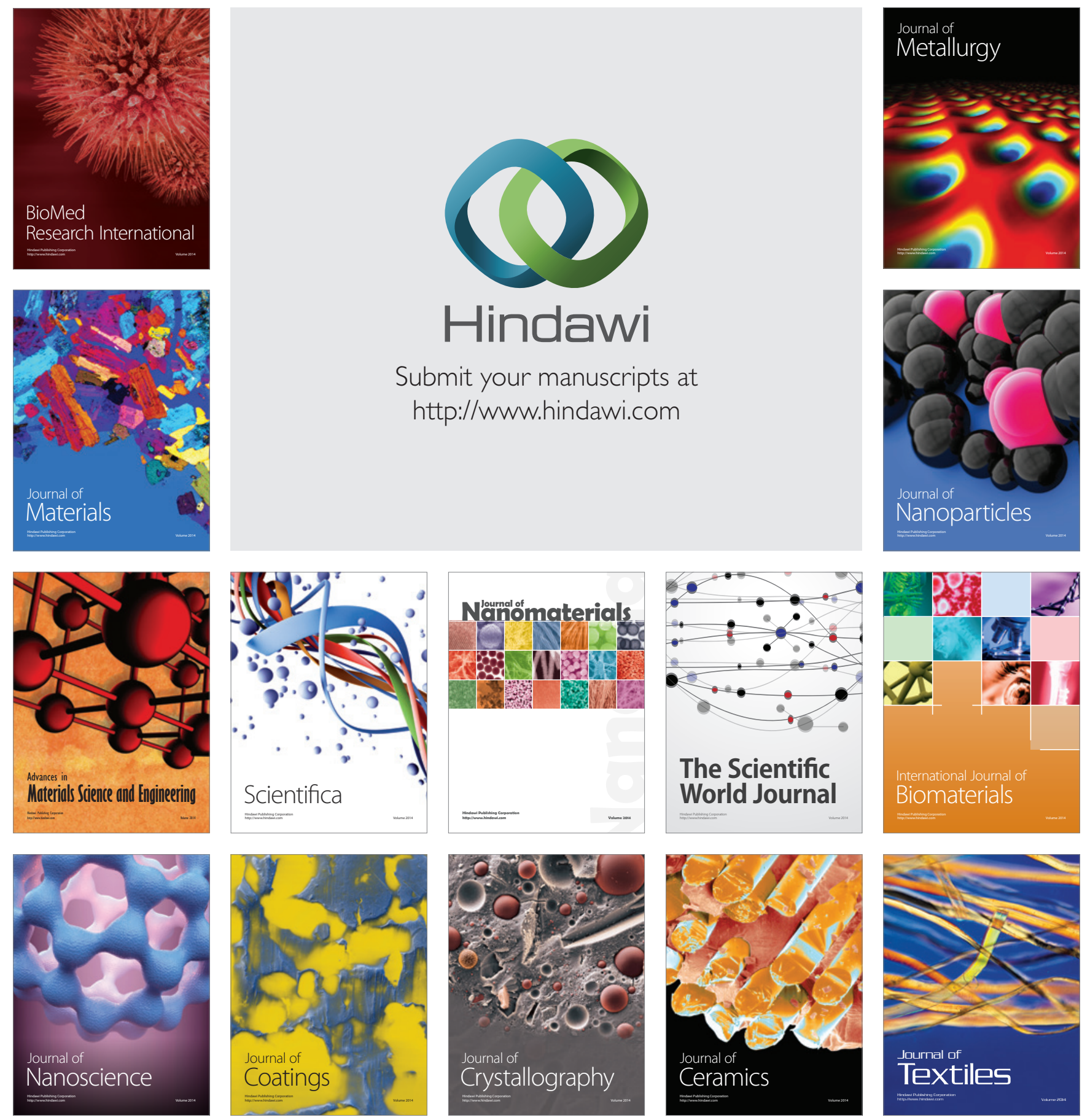